\title{
Sensitivity of chemical tracers to meteorological parameters in the MOZART-3 chemical transport model
}

\author{
D. E. Kinnison, ${ }^{1}$ G. P. Brasseur, ${ }^{1}$ S. Walters, ${ }^{1}$ R. R. Garcia,${ }^{1}$ D. R. Marsh, ${ }^{1}$ F. Sassi, ${ }^{1}$ \\ V. L. Harvey, ${ }^{2}$ C. E. Randall, ${ }^{2}$ L. Emmons, ${ }^{1}$ J. F. Lamarque, ${ }^{1}$ P. Hess, ${ }^{1}$ J. J. Orlando, ${ }^{1}$ \\ X. X. Tie, ${ }^{1}$ W. Randel, ${ }^{1}$ L. L. Pan, ${ }^{1}$ A. Gettelman, ${ }^{1}$ C. Granier, ${ }^{3,4}$ T. Diehl, ${ }^{5}$ U. Niemeier, ${ }^{6}$ \\ and A. J. Simmons ${ }^{7}$
}

Received 3 August 2006; revised 27 April 2007; accepted 27 June 2007; published 17 October 2007.

[1] The Model for Ozone and Related Chemical Tracers, version 3 (MOZART-3), which represents the chemical and physical processes from the troposphere through the lower mesosphere, was used to evaluate the representation of long-lived tracers and ozone using three different meteorological fields. The meteorological fields are based on (1) the Whole Atmosphere Community Climate Model, version 1b (WACCM1b), (2) the European Centre for Medium-Range Weather Forecasts (ECMWF) operational analysis, and (3) a new reanalysis for year 2000 from ECMWF called EXP471. Model-derived tracers (methane, water vapor, and total inorganic nitrogen) and ozone are compared to data climatologies from satellites. Model mean age of air was also derived and compared to in situ $\mathrm{CO}_{2}$ and $\mathrm{SF}_{6}$ data. A detailed analysis of the chemical fields simulated by MOZART-3 shows that even though the general features characterizing the three dynamical sets are rather similar, slight differences in winds and temperature can produce substantial differences in the calculated distributions of chemical tracers. The MOZART-3 simulations that use meteorological fields from WACCM1b and ECMWF EXP471 represented best the distribution of long-lived tracers and mean age of air in the stratosphere. There was a significant improvement using the ECMWF EXP471 reanalysis data product over the ECMWF operational data product. The effect of the quasi-biennial oscillation circulation on long-lived tracers and ozone is examined.

Citation: Kinnison, D. E., et al. (2007), Sensitivity of chemical tracers to meteorological parameters in the MOZART-3 chemical transport model, J. Geophys. Res., 112, D20302, doi:10.1029/2006JD007879.

\section{Introduction}

[2] During the last decade, three-dimensional (3-D) chemical transport models (CTMs) have been developed and used to quantify the global budget of tropospheric and stratospheric chemical compounds, and to simulate their atmospheric transport, chemical transformations and removal from the atmosphere. These numerical tools have also been used to assess the impact of human activities on global air quality. Many of the earlier chemical transport models that were focused on tropospheric physical and chemical processes, extended in altitude only to the tropopause (typically 100-50 hPa) [e.g., Levy et al.,

\footnotetext{
${ }^{1}$ National Center for Atmospheric Research, Boulder, Colorado, USA. ${ }^{2}$ Laboratory for Atmospheric and Space Physics, University of Colorado, Boulder, Colorado, USA.

${ }^{3}$ Aeronomy Laboratory, NOAA, Boulder, Colorado, USA.

${ }^{4}$ Service d'Aéronomie, University of Paris 6, Paris, France.

${ }^{5}$ Goddard Earth Sciences and Technology Center, University of Maryland, Baltimore County, Baltimore, Maryland, USA.

${ }^{6}$ Max Planck Institute for Meteorology, Hamburg, Germany.

${ }^{7}$ European Centre for Medium-Range Weather Forecasts, Reading, UK.
}

Copyright 2007 by the American Geophysical Union. 0148-0227/07/2006JD007879
1985; Crutzen and Zimmerman, 1991; Penner et al., 1991; Roelofs and Lelieveld, 1995; Müller and Brasseur, 1995; Wang et al., 1998] or into the midstratosphere (typically 10-5 hPa) [e.g., Brasseur et al., 1998; Lawrence et al., 1999; Horowitz et al., 2003], and the influence of stratospheric compounds on tropospheric chemistry was expressed by specified upper boundary conditions. For example, in the Model for Ozone and Related Chemical Tracers, version 2 (MOZART-2) [Horowitz et al., 2003], the mixing ratio of species like ozone $\left(\mathrm{O}_{3}\right)$, inorganic nitrogen oxides $\left(\mathrm{NO}_{x}\right)$, and nitric acid $\left(\mathrm{HNO}_{3}\right)$ were specified in the stratosphere according to climatological values, while in the Harvard GEOSCHEM model [Bey et al., 2001], a net stratospheric production was specified for $\mathrm{O}_{3}$, which determined the downward flux of this compound through the tropopause [McLinden et al., 2000]. Several studies [Horowitz et al., 2003; Emmons et al., 2003; Rotman et al., 2004; Gettelman et al., 2004] have shown that the formulation of transport conditions in the vicinity of the tropopause has a large influence on the calculated $\mathrm{O}_{3}$ concentrations in the troposphere, particularly during winter. Different models provide different quantitative values of the cross-tropopause $\mathrm{O}_{3}$ flux, and hence of the global budget of tropospheric $\mathrm{O}_{3}$. 
[3] Since the climate-related interactions between chemical composition and radiative processes are particularly strong near the tropopause, and the vertical concentration gradients of radiatively active species are large in this region of the atmosphere, much care must be put in the representation of dynamical and chemical processes in the upper troposphere/lower stratosphere (UTLS) region. For example, the vertical resolution adopted in this transition region should lead to a sufficiently accurate representation of cross tropopause exchanges as well as detrainment of air from convective regions. A major challenge for modern models is to accurately describe the exchange of chemical compounds across the tropopause, which is strongly affected by synoptic-scale events and other small-scale mixing processes [Pan et al., 2004, 2007].

[4] Several recent studies have highlighted the difficulty of accurately representing dynamical and transport processes in the upper troposphere and lower stratosphere. Douglass et al. [1999], for example, have shown that different meteorological fields used to drive chemical transport models can lead to very different distributions of chemical species in the UTLS region. Specifically, they provide different estimates of the impact on the stratosphere of the exhaust released by aircraft engines in the vicinity of the tropopause. Douglass et al. [2003] showed that, although chemical transport models driven by assimilated fields provide realistic shortterm simulations, the use of dynamical fields produced by atmospheric general circulation models might be more appropriate for long-term simulations of the stratospheric composition. Schoeberl et al. [2003] showed that the assimilation process introduces additional noise in the meridional motions, leading to excessive vertical dispersion and hence to an overestimation of the Brewer-Dobson circulation in the stratosphere. As a result, the mean age of air in the stratosphere [Hall and Plumb, 1994; Hall et al., 1999] is shifted toward values lower than suggested by the observations. Gettelman and Sobel [2000] also showed that assimilation systems could bias estimates of stratospherictropospheric exchange. Recently, van Noije et al. [2004] showed that the enhanced Brewer-Dobson circulation produced by the ERA-40 reanalysis distributed by the European Centre for Middle-Range Weather Forecast (ECMWF) produces an excessive downward flux of $\mathrm{O}_{3}$ across the tropopause. They concluded that simulations could be improved if tropospheric chemical transport models driven by the ECMWF reanalysis, ERA-40, constrain the $\mathrm{O}_{3}$ concentrations in the lower stratosphere by relaxation to climatology (rather than by specifying the net stratospheric ozone source), and use the "forecast" fields rather than the "analysis" (first-guess) fields to calculate the transport of chemical species.

[5] The mean meridional circulation of the lower stratosphere, which affects vertical mass fluxes in the UTLS region, is driven primarily by the "drag" provided by planetary and gravity wave momentum deposition in the stratosphere and mesosphere. The "downward control principle" [Haynes et al., 1991] states that the mean vertical velocity in the vicinity of the tropopause is influenced by momentum sources in the stratosphere, and even up to the lower thermosphere. Therefore global three-dimensional chemical transport models, even if they address issues related to tropospheric processes, should extend to the upper levels of the middle atmosphere. This is a condition for these chemical transport models to adequately represent the meridional transport of atmospheric tracers, the mean age of air in the lower stratosphere, and the flux of chemical constituents through the tropopause [Holton et al., 1995]. Such models need also to treat accurately chemical transformations and, specifically, heterogeneous processes on polar stratospheric cloud (PSC) and aerosol particles.

[6] Three-dimensional chemical transport models with a focus on the middle atmosphere were developed over the last decade [e.g., Rose and Brasseur, 1989; Chipperfield et al., 1993; Rasch et al., 1994; Lefèvre et al., 1994; Brasseur et al., 1997; Douglass et al., 1997; Rotman et al., 2001; Mahowald et al., 2002; Marsh et al., 2003; Rotman et al., 2004; Considine, 2004; Douglass et al., 2004]. These chemical transport models have included gas-phase and heterogeneous reactions that represent realistically the distribution of radicals contained in the $\mathrm{O}_{x}, \mathrm{HO}_{x}, \mathrm{NO}_{x}, \mathrm{ClO}_{x}$, and $\mathrm{BrO}_{x}$ family of constituents that are important for the $\mathrm{O}_{3}$ balance in this region. Only one of these models represented the chemical and physical processes of both the troposphere and stratosphere [Rotman et al., 2004], while another represented in detail the chemical and physical processes of the mesosphere and lower thermosphere [Rose and Brasseur, 1989; Marsh et al., 2003]. Chemical models covering the "entire atmosphere" have recently been coupled "online" to general circulation models. The CTM used in the present study, the Model for Ozone and Related Chemical Tracers, version 3 (MOZART-3) chemical formulation has, for example, been incorporated into the Whole Atmosphere Community Climate Model (WACCM) [Sassi et al., 2005; Lamarque et al., 2006; Eyring et al., 2006; Garcia et al., 2007; Marsh et al., 2007; Tilmes et al., 2007] at the National Center for Atmospheric Research, in Boulder, Colorado, and into the Hamburg Model for Neutral and Ionized Atmosphere (HAMMONIA) [Schmidt et al., 2006] at the Max Planck Institute for Meteorology, in Hamburg, Germany.

[7] Several application studies using MOZART-3 have recently been published [Forkman et al., 2003; Park et al., 2004; Sassi et al., 2004; Gettelman et al., 2004; Kulawik et al., 2006]. The purpose of the present paper is (1) to provide the first detailed description of MOZART-3 (see auxiliary material), (2) to evaluate the distributions of chemical compounds calculated using different meteorological fields, with an emphasis on the middle atmosphere region, (3) to highlight the role including a quasi-biennial oscillation has in modifying stratospheric ozone and its precursors, and (4) to assess whether the new reanalysis meteorological products provided by ECMWF are suitable for future studies that include satellite observations to better understand stratospheric physical, dynamical, and chemical processes. ${ }^{1}$ Specifically, this paper investigates the sensitivity of the calculated tracer distributions and mean age of air to the adopted temperature and wind fields, and assesses the impact of different physical and dynamical processes on the distribution of water vapor $\left(\mathrm{H}_{2} \mathrm{O}\right)$ and $\mathrm{O}_{3}$ in the middle atmosphere.

\footnotetext{
${ }^{1}$ Auxiliary material data sets are available at $\mathrm{ftp} / / \mathrm{ftp}$.agu.org/apend/jd/ 2006jd007879. Other auxiliary material files are in the HTML.
} 
Table 1. Model Simulations

\begin{tabular}{|c|c|c|c|c|c|}
\hline Case & Name & Meteorological Fields & Horizontal Resolution & Vertical Resolution & Vertical Domain \\
\hline 1 & MZ3-WA1b & WACCM, version $1 \mathrm{~b}$ & $2.8^{0} \times 2.8^{\circ}$ & $\begin{array}{l}\text { Troposphere: } 1 \mathrm{~km} \\
\text { UTLS: } 1.2 \mathrm{~km} \\
\text { Stratosphere: } 2-3 \mathrm{~km} \\
\text { Mesosphere: } 3 \mathrm{~km}\end{array}$ & $0-150 \mathrm{~km}$ \\
\hline 2 & MZ3-Op & ECMWF operational year 2000 & $1.9^{\circ} \times 1.9^{\circ}$ & $\begin{array}{l}\text { Troposphere: } 0.5 \mathrm{~km} \\
\text { UTLS: } 1 \mathrm{~km} \\
\text { Stratosphere: } 1.5-2 \mathrm{~km}\end{array}$ & $0-65 \mathrm{~km}$ \\
\hline 3 & MZ3-EXP471 & $\begin{array}{c}\text { ECMWF reanalysis } \\
\text { version EXP471 year } 2000\end{array}$ & $1.9^{\circ} \times 1.9^{\circ}$ & $\begin{array}{l}\text { Troposphere: } 0.5 \mathrm{~km} \\
\text { UTLS: } 1 \mathrm{~km} \\
\text { Stratosphere: } 1.5-2 \mathrm{~km}\end{array}$ & $0-65 \mathrm{~km}$ \\
\hline
\end{tabular}

\section{Model Description}

[8] The MOZART model, version 3 (MOZART-3), was designed to represent chemical and physical processes from the troposphere through the lower thermosphere. This model is an extension to the middle atmosphere of the global tropospheric models MOZART-1 [Brasseur et al., 1998; Hauglustaine et al., 1998] and MOZART-2 [Horowitz et al., 2003; Emmons et al., 2003]. MOZART-3 is designed in a framework similar to the earlier versions of MOZART, but accounts for additional processes such as (1) vertical mixing associated with gravity wave breaking in the upper stratosphere/mesosphere, (2) molecular diffusion of constituents important above $80 \mathrm{~km}$, (3) source gases, radicals, chemical and photochemical reactions to represent the $\mathrm{ClO}_{x}$ and $\mathrm{BrO}_{x}$ families of constituents, (4) stratospheric sulfate aerosols and polar stratospheric clouds (PSCs) to represent stratospheric heterogeneous processes and subsequent $\mathrm{O}_{3}$ loss, (5) photolysis to wavelengths as short as $120 \mathrm{~nm}$, important for upper stratosphere and mesosphere photochemistry, and (6) auroral $\mathrm{NO}_{x}$ production for better representation of high-latitude $\mathrm{NO}_{x}$ and $\mathrm{O}_{3}$ photochemistry.

[9] MOZART-3 is similar to MOZART-2 [Horowitz et al., 2003] in that a detailed formulation of physical processes in the troposphere is included (e.g., boundary layer exchanges, convective transport, and hydrological cycle) (based on the Model for Atmospheric Transport and Chemistry (MATCH) [Rasch et al., 1997]). Meteorological fields (e.g., temperature and horizontal wind components) are needed to drive the transport of chemical compounds as well as the hydrological cycle (cloudiness, precipitation, etc.; see auxiliary material). These dynamical fields are provided either from a general circulation model simulation or from meteorological analyses produced through operational weather prediction or reanalysis.

[10] The vertical velocities are derived in MOZART-3 from the divergence of the horizontal velocity fields, using an advection routine based on the work of Lin and Rood [1996]. This routine is a numerically fast, flux form semiLagrangian transport scheme. Therefore the vertical velocities of the parent General Circulation Model (GCM) are not used. One consequence of using meteorological fields from GCMs is that the time evolution of the divergence of the meteorological fields may not be consistent with the time evolution of the surface pressure field. This issue is discussed in detail by Horowitz et al. [2003] and Rotman et al. [2004]. For the results shown in this paper, the error associated with adding in a surface pressure adjustment on the mass conservation of stratospheric consistents (e.g., ozone) is negligible.

[11] A detailed description of the approaches adopted in MOZART-3 to account for meteorological and transport processes, surface emission and deposition of chemical species, gas-phase and heterogeneous processes, as well as the numerical algorithms used to solve the corresponding continuity transport equations is contained in the auxiliary material.

\section{Model Simulations}

[12] Three sets of meteorological fields are used to drive MOZART-3 in this study. Below is a brief description of each set and of how the fields were used in the simulations reported here. See also Table 1.

\subsection{Case 1: Dynamical Fields From the WACCM1b Model}

[13] The Whole Atmosphere Community Climate Model, version $1 \mathrm{~b}$ (WACCM1b) is a comprehensive model, spanning the range of altitudes from the Earth's surface to the lower thermosphere [Sassi et al., 2004]. This model is built upon the numerical framework of the NCAR Community Climate System Model (CCSM). The horizontal resolution is $2.8^{\circ} \times 2.8^{\circ}$, with $128 \times 64$ points in a quasi-linear grid [Williamson, 1997]. There are 66 vertical levels from the surface to approximately $150 \mathrm{~km}$. The vertical resolution of WACCM1b is less than $1 \mathrm{~km}$ in the troposphere, and approximately $1.2 \mathrm{~km}$ in the UTLS region; it increases to $2-3 \mathrm{~km}$ in the stratosphere and to $\sim 3 \mathrm{~km}$ in the mesosphere/lower thermosphere (M/LT). The dynamical governing equations are solved with a semi-Lagrangian technique [Williamson and Olson, 1994].

\subsection{Case 2: Dynamical Fields From ECMWF Operational Analysis}

[14] Operational meteorological fields for the year 2000 produced by the European Centre for Medium-Range Weather Forecasts (ECMWF; http://www.ecmwf.int/) are used in this study. Like WACCM1b, the assimilation model used to derive these meteorological fields is based on a semi-Lagrangian treatment of atmospheric dynamics and a comprehensive representation of physical processes. The operational analysis system uses four-dimensional variational (4D-Var) assimilation. During 2000, this 4D-Var system was changed from 6- to 12-hour cycling in September and spectral horizontal resolution was changed from 
T319 to T511 truncation in November. For use in MOZART-3, the archived meteorological fields are reduced to a uniform lower resolution by truncation to T63, consistent with an N48 Gaussian grid of horizontal resolution $1.9^{\circ} \times$ $1.9^{\circ}$. They are defined on 60 levels from the surface to approximately $65 \mathrm{~km}$, with vertical resolution about $0.5 \mathrm{~km}$ in the midtroposphere, around $1 \mathrm{~km}$ in the UTLS region, and close to $1.5 \mathrm{~km}$ for most of the stratosphere.

\subsection{Case 3: Dynamical Fields From the ECMWF EXP471 Reanalysis}

[15] The ECMWF reanalysis called ERA-40 was produced by a 3D-Var data assimilation technique using 6-hourly cycling. The assimilating atmospheric model had T159 spectral truncation in the horizontal (using a linear reduced Gaussian grid with $\sim 125 \mathrm{~km}$ spacing), and the same 60 -level vertical resolution as used in the operational analysis system. The model and the assimilation system are described in detail by Uppala et al. [2005].

[16] Because of known deficiencies in ERA-40 fields for simulation of long-term chemical transport [e.g., van Noije et al., 2004; Uppala et al., 2005], we use here an updated set of ECMWF reanalysis fields for the year 2000. The updated reanalysis, which is designated EXP471, is one of several carried out for particular time segments as part of the development of an improved assimilation system to be used for a new reanalysis of the period from 1989 onward. The assimilation system for EXP471 used the same resolution as ERA-40, but used 4D-Var rather than 3D-Var analyses, with 12-hourly rather than 6-hourly cycling. It benefited also from many changes developed for the operational ECMWF system over the period since 2001, when the ERA-40 system was fixed. These changes include revisions in the amount, type, bias correction and quality control of ingested data, in the humidity analysis, in the dynamical background error constraint, and in the assimilating model's parameterizations of convection and radiation. It was not feasible to evaluate the changes individually over test periods long enough to quantify the separate impact of each on key features such as the implied age of stratospheric air. MongeSanz et al. [2007] discuss the changes most likely to have had significant effect. As done for the operational analyses, the reanalysis data have been truncated to T63 and evaluated on the corresponding N48 grid.

\subsection{Simulations}

[17] The WACCM1b model was integrated from 1979 to 2001 using observed sea surface temperatures and greenhouse gas abundances [Sassi et al., 2004]. High-frequency (3-hour average) meteorological output from this simulation was created for MOZART-3. The WACCM1b year 1999 was chosen for this study because it had meteorological conditions similar to the ECMWF year 2000 for the stratosphere in Northern Hemisphere winter/spring. MOZART-3 was integrated for multiple years (using repeatedly this meteorological year) until the model was in steady state with respect to stratospheric $\mathrm{O}_{3}$. The last year of the simulation was used in this study. In what follows, this MOZART-3 WACCM1b simulation will be designated as MZ3-WA1b (case 1).

[18] The MOZART-3 ECMWF operational and ECMWF EXP471 simulations were integrated in a similar manner.
Input meteorology was on a 6-hour average interval. The MOZART-3 model was integrated for multiple years for each set of meteorological fields, until the derived $\mathrm{O}_{3}$ reached steady state in the stratosphere. The last year of the simulation was used in this study. In the following discussion, these simulations will be designated as MZ3-Op (case 2) and MZ3-EXP471 (case 3). MZ3-ECMWF will refer to both of the simulations.

[19] For all three cases examined in the paper, the sulfate surface area density was derived from year 1999 observations [Thomason et al., 1997] (as updated by World Meteorological Organization (WMO) [2003]). Surface boundary conditions for $\mathrm{CO}_{2}, \mathrm{CH}_{4}, \mathrm{~N}_{2} \mathrm{O}, \mathrm{H}_{2}, \mathrm{CH}_{3} \mathrm{Cl}, \mathrm{CCl}_{4}, \mathrm{CH}_{3} \mathrm{CCl}_{3}$, $\mathrm{CFCl}_{3}, \mathrm{CF}_{2} \mathrm{Cl}_{2}, \mathrm{CFC}-113, \mathrm{HCFC}-22, \mathrm{CH}_{3} \mathrm{Cl}, \mathrm{CH}_{3} \mathrm{Br}$, $\mathrm{CF}_{3} \mathrm{Br}$, and $\mathrm{CF}_{2} \mathrm{ClBr}$ are constrained by observations (see auxiliary material for references). These surface boundary conditions were set to 1999 conditions for the MZ3-WA1b case and 2000 conditions for the MZ3-ECMWF cases.

[20] For the mean age-of-air simulations, a tracer version of MOZART-3 was created. Here a flux is specified that increases the atmospheric burden linearly in time. This tracer is conserved (i.e., there are no loss processes in the atmosphere). The behavior of such a tracer is similar to the observed temporal evolution of $\mathrm{SF}_{6}$. The mean age of air in the middle atmosphere was derived relative to the tropical tropopause. This procedure is discussed in more detail by Garcia et al. [2007]. The age of air was integrated with the meteorological fields corresponding to the 3 model cases until steady state conditions were reached (approximately 15 years).

\subsection{Observations}

[21] Three observational data sets are used in this study for comparison to the model simulations. For $\mathrm{CH}_{4}, \mathrm{H}_{2} \mathrm{O}$, $\mathrm{NO}_{y}$, and $\mathrm{O}_{3}$ we use a climatology derived from instruments on board the Upper Atmosphere Research Satellite (UARS). For comparisons to this satellite climatology, we are only interested in how representative the MOZART-3 simulation results are with respect to climatological means (i.e., we do not attempt to compare specific features in the simulation to satellite products on a given date). We also examine the evolution of $\mathrm{O}_{3}$ and $\mathrm{H}_{2} \mathrm{O}$ from an occultation instrument that samples high-latitude regions in both hemispheres. Here we give both the climatological mean (for comparison to MZ3-WA1b) and the results from year 2000 (to compare with the MZ3-ECMWF cases). We also examine the evolution of total column ozone. In this case we are primarily interested in how the MZ3-ECMWF simulations agree with total column ozone derived for year 2000. Below is a brief description of each data set.

\subsubsection{POAM III: Ozone and Water Vapor}

[22] The Polar Ozone and Aerosol Measurement (POAM) III instrument [Lucke et al., 1999] was launched into a polar, Sun synchronous orbit in March of 1998, and operated until December of 2005. POAM III measured vertical profiles of $\mathrm{O}_{3}, \mathrm{NO}_{2}, \mathrm{H}_{2} \mathrm{O}$, and aerosol extinction using the solar occultation technique with nine wavelength channels ranging from $353 \mathrm{~nm}$ to $1018 \mathrm{~nm}$. Because of its high-inclination orbit, measurements could be obtained in the polar regions throughout the year. Each day, 14 occultations separated by about 25 degrees in longitude were made around a circle of approximately constant latitude. Latitudes 
varied slowly throughout the year, between about $54^{\circ}$ and $71^{\circ}$ in the Northern Hemisphere, and $63^{\circ}$ and $68^{\circ}$ in the Southern Hemisphere. (A map of latitude points where observations are made is included in Figure 14.) There are 43,404 total occultations incorporated in the 1998-2005 climatology used in this study. The POAM III inversion algorithm, which utilizes the optimal estimation technique to simultaneously retrieve vertical profiles of all of the measured constituents, has been described in detail by Lumpe et al. [2002].

[23] Lumpe et al. [2006] validated the POAM III v4.0 $\mathrm{H}_{2} \mathrm{O}$ retrievals. The $\mathrm{H}_{2} \mathrm{O}$ profiles extend from 5 to $50 \mathrm{~km}$, with a vertical resolution of $1 \mathrm{~km}$ in the lower stratosphere, $3 \mathrm{~km}$ in the upper stratosphere, and 5-7\% precision throughout the stratosphere. Comparisons with correlative measurements performed by Lumpe et al. [2006] suggest a high bias in the Northern Hemisphere POAM measurements (satellite sunrise occultations) of about $5-10 \%$ in the altitude range of $12-35 \mathrm{~km}$. The Southern Hemisphere measurements (satellite sunset occultations) exhibit a high bias of about $15-25 \%$ in the same range of altitude. Differences between POAM measurements and correlative data decrease at higher altitudes. In the Northern Hemisphere, POAM agrees with other measurements at $40 \mathrm{~km}$, and is $10 \%$ low by $50 \mathrm{~km}$. The high bias in the Southern Hemisphere decreases to about $10 \%$ by $50 \mathrm{~km}$. In spite of these systematic differences in the correlative comparisons, the POAM $\mathrm{H}_{2} \mathrm{O}$ measurements were found to be selfconsistent, with no long-term trends in accuracy or precision [Lumpe et al., 2006].

[24] Randall et al. [2003] validated the POAM III v3.0 $\mathrm{O}_{3}$ retrievals, showing that the POAM data agree with correlative measurements to within $\pm 5 \%$ from $13-60 \mathrm{~km}$. The $\mathrm{O}_{3}$ retrievals exhibit a high bias compared to correlative measurements of up to $\sim 0.1$ ppmv from $10-12 \mathrm{~km}$. POAM III $\mathrm{O}_{3}$ retrievals have a vertical resolution of $1 \mathrm{~km}$ from 15 to $50 \mathrm{~km}$, increasing to $1.5 \mathrm{~km}$ at an altitude of $10 \mathrm{~km}$ and $2.5 \mathrm{~km}$ at an altitude of $60 \mathrm{~km}$. Random errors are about $\sim 5 \%$ or less above $12 \mathrm{~km}$. As described by Lumpe et al. [2006], the primary improvements in the version 4.0 retrievals used here over version 3.0 involve changes in how the instrument pointing was calculated, and in the parameterization of the spectral dependence of aerosol extinction. These improvements had only very small effects on the POAM III $\mathrm{O}_{3}$ retrievals, however, and the conclusions of Randall et al. [2003] apply to version 4.0.

\subsubsection{EP/TOMS: Total Column Ozone}

[25] The Earth Probe Total Ozone Mapping Spectrometer (EP/TOMS) is currently operating in a $740 \mathrm{~km}$, Sun synchronous orbit. The inclination is $98.4^{\circ}$ with a period of 99.65 minutes. The equatorial crossing time is 11:16 AM. The EP/TOMS field of view at nadir is $39 \mathrm{~km}$ latitude by $39 \mathrm{~km}$ longitude. The current orbital characteristics of EP/ TOMS give $90 \%$ daily global coverage. Data used in this study are taken from the NASA Goddard Space Flight Centers web page http://toms.gsfc.nasa.gov/eptoms/ ep.html). Daily zonal mean total column ozone data (in Dobson Units) were averaged into $5^{\circ}$ latitude bins for year 2000 by the EP/TOMS science team. The total ozone retrieval gives an absolute error of \pm 3 percent; the random error is approximately \pm 2 percent. More detailed informa- tion on accuracy, precision, and coverage for EP/TOMS is given by McPeters et al. [1998].

\subsubsection{UARS Climatology: $\mathrm{CH}_{4}, \mathrm{H}_{2} \mathrm{O}, \mathrm{NO}_{y}$, and $\mathrm{O}_{3}$}

[26] Details regarding the UARS climatology used in this study are given by Randel et al. [1998]. These data were mapped onto an equivalent latitude coordinate. The monthly mean methane $\left(\mathrm{CH}_{4}\right)$ and $\mathrm{H}_{2} \mathrm{O}$ climatologies are based primarily on version 18 Halogen Occultation Experiment (HALOE) data between 1991 and 1997. To fill in the polar regions not sampled by HALOE, the Cryogenic Limb Array Etalon Spectrometer (CLAES) version 7 data and the Microwave Limb Sounder (MLS) version 4 data were used for $\mathrm{CH}_{4}$ and $\mathrm{H}_{2} \mathrm{O}$, respectively. Data from these two instruments were obtained during 1992-1993. Ozone data were primarily taken from HALOE, with MLS data for 19911997 used in the polar regions. Total inorganic odd nitrogen $\left(\mathrm{NO}_{y}\right)$ from observations are defined by summing the $\mathrm{NO}+$ $\mathrm{NO}_{2}$ sunset data observed by HALOE and adding it to the $\mathrm{HNO}_{3}$ data observed by CLAES. The definition of $\mathrm{NO}_{y}$ in the model is slightly different, as explained in section 4.2.

\section{Model Results and Discussion}

[27] The evaluation of MOZART-3 driven with the above mentioned meteorological fields is divided into four sections. The first section examines similarities and differences between the input zonal winds and temperature fields. The second section compares modeled and observed long-lived tracers as surrogates for the global circulation and transport processes. The third section examines model representation of total column ozone and polar processes. The goal of these sections is to show that accurate representation of temperature, dynamics, and transport is critical for achieving realistic chemical distributions, and specifically for obtaining correct distributions of long-lived tracers and of ozone.

\subsection{Zonal Winds and Temperature Comparisons}

[28] In Figure 1, the latitude-altitude monthly mean zonal wind distributions are shown for January, March, July, and October. Solid lines represent zonal wind propagation from the west (westerlies); dotted lines represent zonal wind propagation from the east (easterlies). In January the WACCM1b zonal winds are similar to the ECMWF zonal winds, except for the presence in the ECMWF data of a westerly jet in the tropics, centered at $50 \mathrm{hPa}$. It is well known that the zonal winds in the lower stratosphere shift direction from easterlies to westerlies with a period of approximately 27 months, a feature known as the quasibiennial oscillation (QBO). The year 2000 ECMWF zonal winds show a clear QBO westerly structure in the tropical stratosphere (as well as an enhancement of the easterly winds near $10 \mathrm{mb}$ ). The WACCM1b zonal winds are lacking these features because the QBO is not simulated in the parent WACCM1b model. Instead, the tropical stratosphere in the WACCM1b simulation is in a permanent easterly phase. The importance of the QBO on tracer distributions will be examined in section 4.2. In March, there are differences between the Op and EXP471 zonal winds near $1 \mathrm{hPa}$. Here the EXP471 zonal winds are westerly, whereas the Op zonal winds are easterly. This region of the tropical stratosphere is influenced by a semiannual oscillation (SAO) in the zonal winds, and 

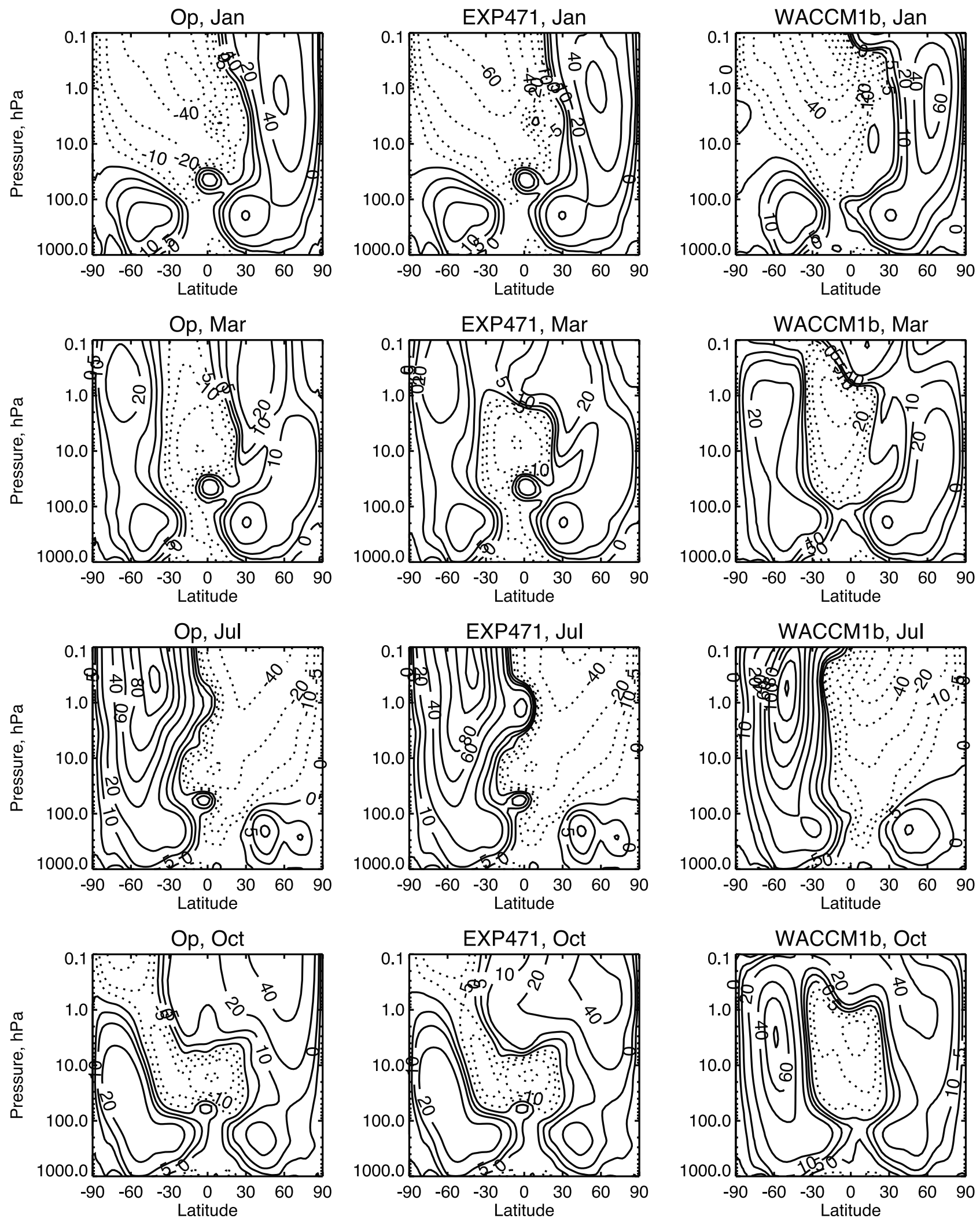

Figure 1. Latitude-altitude cross sections of zonal mean zonal winds $\left(\mathrm{m} \mathrm{s}^{-1}\right)$ for January, March, July, and October for the ECMWF Operational, ECMWF EXP471, and WACCM1b meteorological fields. 
WACCM1b has a SAO signature similar to EXP471. WACCM1b zonal winds in the winter hemisphere are generally stronger than in the ECMWF meteorological fields; this is especially true in the Southern Hemisphere winter (July) and in the transition from winter to spring (October), which occurs too late in the model. Thus WACCM1b retains westerlies through $0.1 \mathrm{hPa}$, while in the ECMWF meteorological fields there are easterlies above $1 \mathrm{hPa}$. The importance of this bias in WACCM1b meteorology can be seen in the Southern Hemisphere temperature distribution.

[29] In Figure 2 the zonal monthly mean temperatures are shown for the three MOZART-3 simulations during January, March, July, and October. Year 2000 was a cold year in the Northern Hemisphere [Sabutis and Manney, 2000], with minimum ECMWF temperature approaching $190 \mathrm{~K}$ in January. Results from both Op and EXP471 are similar in this figure. The WACCM1b temperatures for January, in the polar Northern Hemisphere are also similar to ECMWF results. At these temperatures in the polar lower stratosphere, one would expect significant activation of inorganic chlorine reservoir species. In March, the WACCM1b zonal monthly mean Northern Hemisphere polar temperatures are $5 \mathrm{~K}$ colder than the ECMWF meteorological products in the polar lower stratosphere. This promotes more springtime $\mathrm{O}_{3}$ loss in the MZ3-WA1b simulation relative to the two MZ3-ECMWF simulations. In July, the ECMWF and WACCM1b temperatures approach $180 \mathrm{~K}$ in the Southern Hemisphere polar lower stratosphere. These cold temperatures extend lower in pressure (higher in altitude) in the WACCM1b fields relative to the ECMWF fields; this will have consequences for dehydration between the simulations. In October, the Southern Hemisphere temperatures in WACCM1b in the polar lower stratosphere are colder and this cold region has a vertical extent that is broader in altitude than the ECMWF meteorological products. This will tend to promote more $\mathrm{O}_{3}$ loss over a larger vertical area in the MZ3-WA1b simulation relative to MZ3-Op and MZ3EXP471.

[30] The evolution of the daily zonal mean temperatures in the polar lower stratosphere and equatorial UTLS region are shown in Figure 3. At $84^{\circ} \mathrm{S}$ there are noticeable differences between EXP471 and Op temperatures, with EXP471 being 3-4 $\mathrm{K}$ colder in winter/spring. Temperatures from EXP471 are more similar to WACCM1b in this region up to mid-October, when there is a final warming in EXP471, but not in WACCM1b. In the latter case, the Southern Hemisphere vortex stays isolated late into the spring, which causes the $\mathrm{O}_{3}$ distribution in MZ3-WA1b simulation to be different from those in the MZ3-ECMWF simulations. The cold bias in temperature and isolation of the Southern Hemisphere vortex in WACCM1b is consistent with the zonal wind distributions shown in Figure 1 . At $84^{\circ} \mathrm{N}$, the Op and EXP471 temperatures are very similar throughout the year. The ECMWF temperatures are also fairly consistent with WACCM1b temperatures until late winter/early spring when the ECMWF temperatures become warmer than the WACCM1b temperatures. In the tropics, at the cold point ( $85 \mathrm{hPa}$ and $96 \mathrm{hPa}$ for WACCM1b and ECMWF respectively), January and February differ among the Op, EXP471, and WACCM1b cases, with WACCM1b being the coldest and EXP471 being the warmest. WACCM1b also has a larger seasonal amplitude in temperature than the ECMWF temperature products. The most significant difference between WACCM1b and the ECMWF temperatures are seen in November and December, when both ECMWF temperature products have temperature distributions that are colder by up to $4 \mathrm{~K}$ relative to WACCM $1 \mathrm{~b}$. This difference in temperatures will be seen in the evolution of the $\mathrm{H}_{2} \mathrm{O}$ in section 4.2.

[31] It should be noted that in the following sections the comparisons of calculated chemical fields for specific meteorological years are compared to various observational chemical climatologies. Agreement or disagreement between model results and observational climatologies in a broad sense can be instructive, although specific features in either the climatology or model results should not be overinterpreted. This approach can help discriminate between the effects of the different dynamical fields on chemical distributions. An example of how this analysis approach has been successful is given by Douglass et al. [1999].

\subsection{Global Circulation and Transport}

[32] One measure of the representation of the global circulation and transport is the mean age of air derived in a model [Hall and Plumb, 1994; Hall et al., 1999; Waugh and Hall, 2002]. In Figure 4 (top), the annual average mean age of air is shown for the Op, EXP471, and WACCM1b meteorological fields. Figure 4 (bottom) shows the difference between the Op and WACCM1b cases relative to the EXP471 case. Corresponding comparisons for the Op and EXP471 analysis, and for ERA-40 and UK Met Office analysis, using the TOMCAT transport model have been reported by Monge-Sanz et al. [2007]. The mean age of air from the MZ3-Op simulation is significantly younger than both the MZ3-EXP471 and MZ3-WA1b simulations. The maximum mean age of air for the MZ3-Op simulation is less than 4 years. The maximum mean age of air for the MZ3-EXP471 and MZ3-WA1b simulations is 4.0 and 4.5 years, respectively. The shapes of the mean age-of-air isopleths are also very different for each meteorological product. The derived MZ3-Op mean age of air shows weak meridional gradients throughout the lower stratosphere. In contrast, the derived MZ3-EXP471 mean age of air has strong gradients in the lower stratosphere at $20^{\circ} \mathrm{N}$ and $20^{\circ} \mathrm{S}$. Here the mean age-of-air isopleths are essentially constant in the MZ3-EXP471 simulation at altitudes between 18 $28 \mathrm{~km}$, suggesting a strong lower stratosphere midlatitude barrier to horizontal transport between the tropics and subtropics. The derived mean age of air for the MZ3WA1b simulation does not show such a strong apparent barrier to transport in this region. However, the annual average gradients are larger in the $\pm 45-60^{\circ}$ and $10-15 \mathrm{~km}$ region in MZ3-WA1b relative to both MZ3-ECMWF simulations. In the tropics, between 30 and $40 \mathrm{~km}$, the mean age-of-air isopleths in the MZ3-WA1b simulation have strong meridional gradients, suggestive of a more isolated tropical region in this simulation. This is consistent with long-lived tracer distributions discussed below. In Figure 5a, a mean age-of-air latitudinal cross section is shown at $20 \mathrm{~km}$ for both models and observations [Boering et al., 1996; Andrews et al., 2001; Elkins et al., 1996; Ray et al., 1999; see also Monge-Sanz et al., 2007]. The observational estimates of the mean age of air are based on measurements 

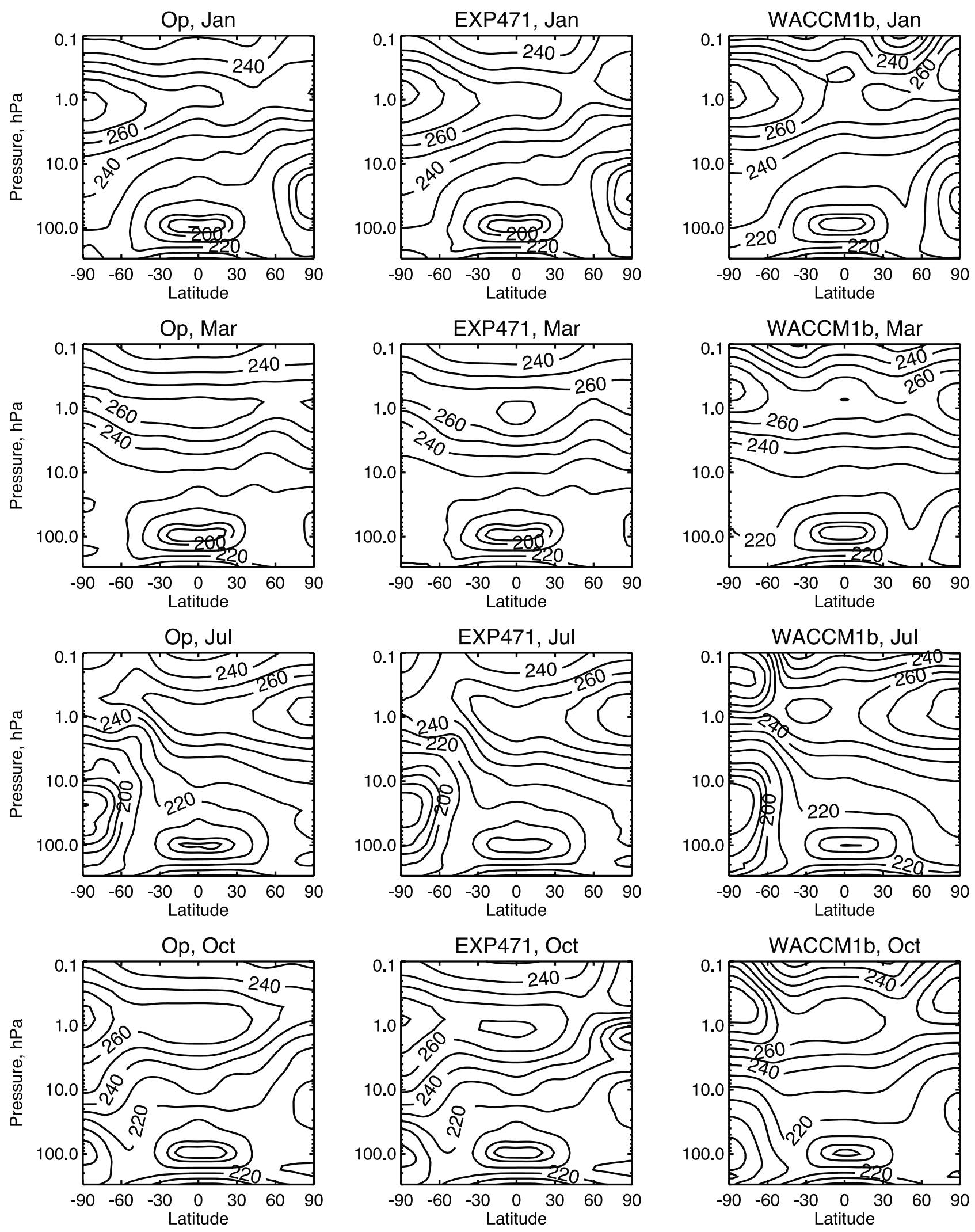

Figure 2. Latitude-altitude cross sections of zonal mean temperature (K) for January, March, July, and October for the ECMWF Operational, ECMWF EXP471, and WACCM1b meteorological fields. Contour intervals are $180-200 \mathrm{~K}$ by units of $5 \mathrm{~K}$ and $200-300 \mathrm{~K}$ by units of $10 \mathrm{~K}$. 

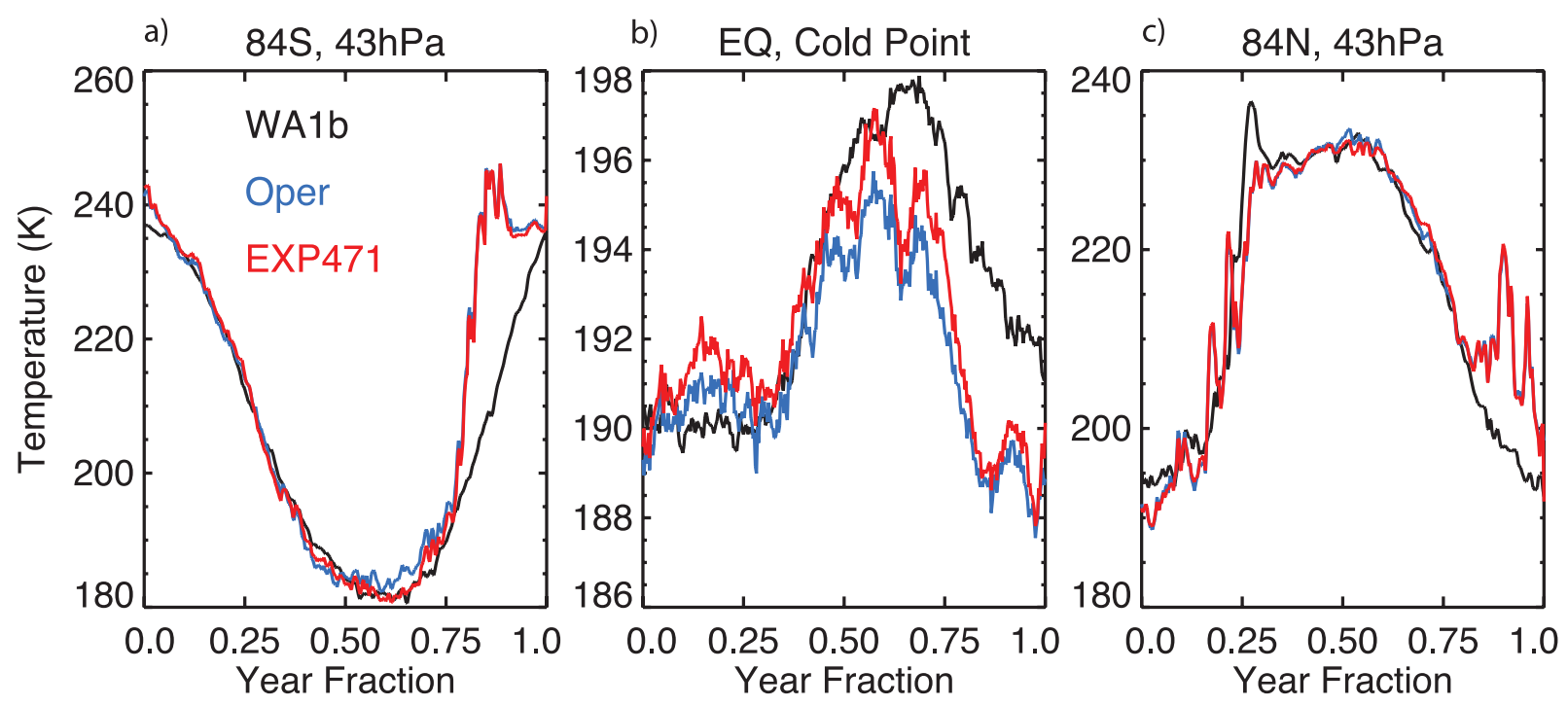

Figure 3. Annual cycle of zonal mean temperatures (K) at $43 \mathrm{hPa}$ for ECMWF operational (blue), ECMWF EXP471 (red), and WACCM1b (black) meteorological fields (a) for $84^{\circ} \mathrm{S}$, (b) at the tropical cold point temperature $(85 \mathrm{hPa}$ for WACCM1b and $96 \mathrm{hPa}$ for ECMWF meteorological fields), and (c) for $84^{\circ} \mathrm{N}$.

of $\mathrm{CO}_{2}$ and $\mathrm{SF}_{6}$. Overall, the MZ3-WA1b simulation better represents the observations at $20 \mathrm{~km}$. In Figure 5b, the mean age-of-air $7^{\circ} \mathrm{S}$ profiles are shown. At $7^{\circ} \mathrm{S}$, the MZ3-EXP471 simulation better represents the observations between 17 and $22 \mathrm{~km}$. At $7^{\circ} \mathrm{S}$, all three model simulations greatly underestimate the mean age of air above $22 \mathrm{~km}$. Even at $12^{\circ} \mathrm{S}$ (not shown), the three simulations underestimate the observed mean age of air at $7^{\circ} \mathrm{S}$ (above $22 \mathrm{~km}$ ). Therefore,
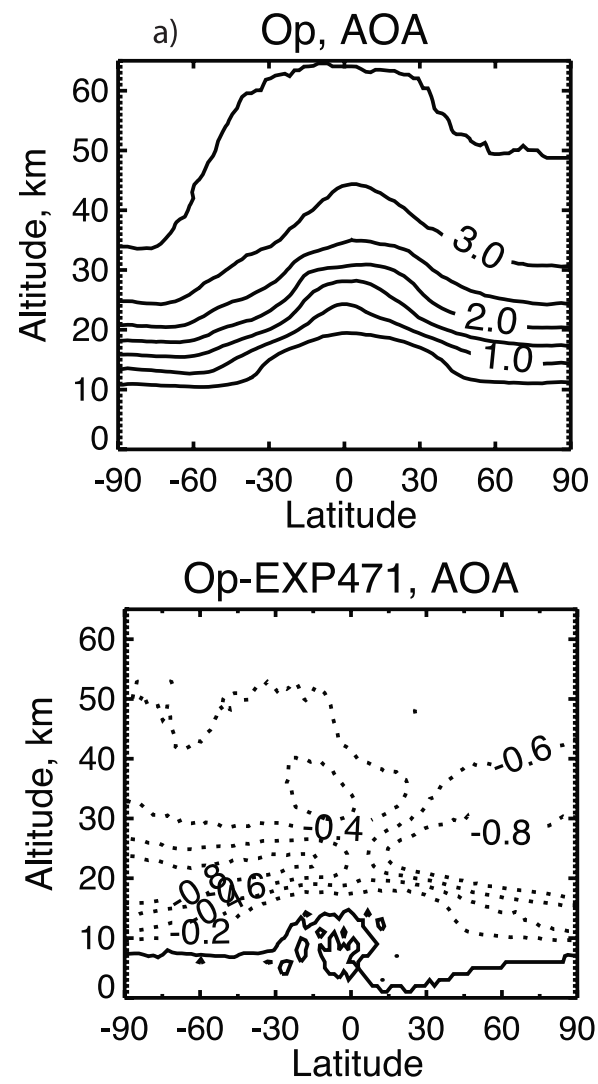

b) EXP471, AOA
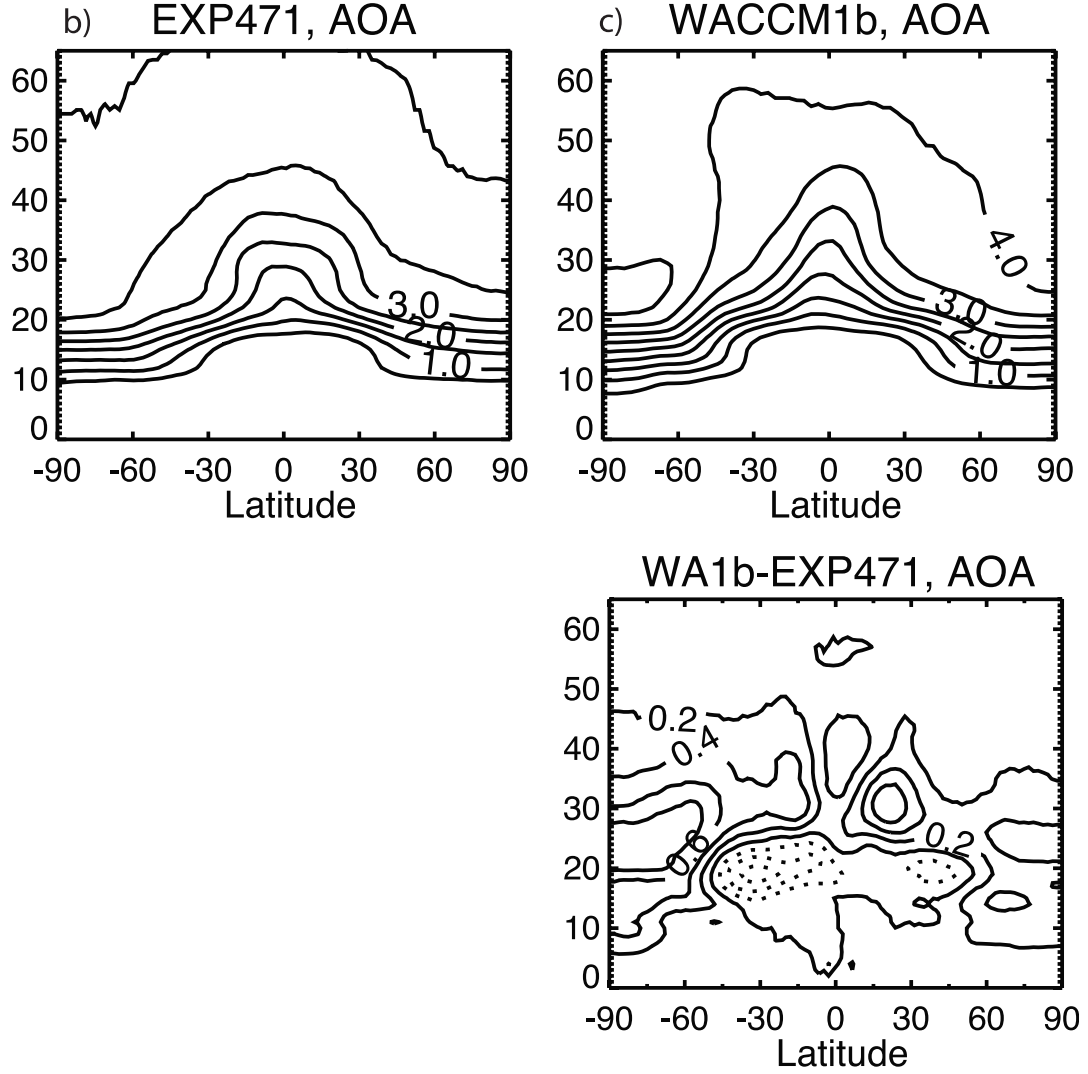

Figure 4. Latitude-altitude cross sections of the annual average mean age of air (in years) for (a) MZ3Op, (b) MZ3-EXP471, and (c) MZ3-WA1b. The mean age-of-air isopleths are separated by 0.5 years. (bottom) The difference between the MZ3-Op and MZ3-WA1b simulations relative to the MZ3-EXP471 simulation. For this comparison, the mean age-of-air isopleths are separated by \pm 0.2 years. 
a) Mean Age at $20 \mathrm{~km}$

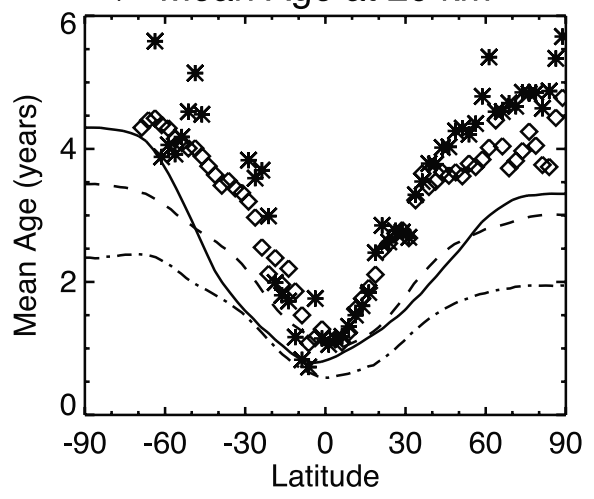

b) Mean Age at 7S

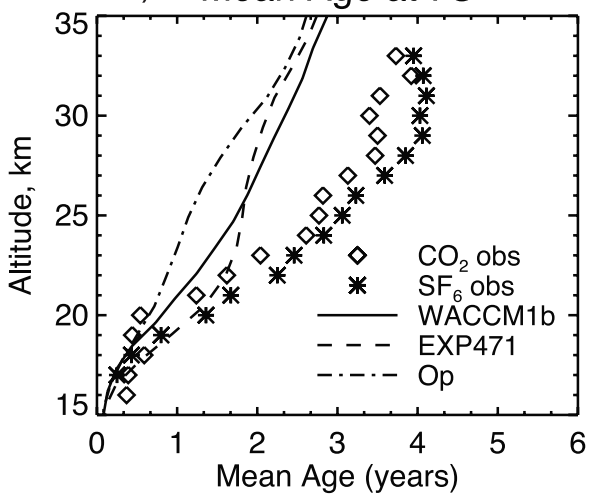

Figure 5. (a) Mean age of air at $20 \mathrm{~km}$ for MZ3-Op, MZ3-EXP471, and MZ3-WA1b along with the mean age of air derived from balloon and aircraft observations of $\mathrm{CO}_{2}$ (diamond) and $\mathrm{SF}_{6}$ (asterisk). (b) Profiles of mean age of air at $7^{\circ} \mathrm{S}$ for the same three simulations and observations derived from balloon flights.

above $22 \mathrm{~km}$, the tropics are younger in a broader region than observations would suggest. At $24^{\circ} \mathrm{S}$ (not shown), the three simulations have air that is significantly older, however, only the MZ3-WA1b simulation mean age of air approaches the mean age of air derived from observations at $7^{\circ} \mathrm{S}$. The model dynamics and transport that leads to having too young mean age of air will be discussed in more detail below.

[33] One diagnostic of the effect of input dynamics and temperature on model derived chemical constituents is the photochemical lifetime. In Table 2, the model photochemical lifetime with respect to loss processes are shown for $\mathrm{CH}_{4}, \mathrm{~N}_{2} \mathrm{O}, \mathrm{CFC}-11, \mathrm{CFC}-12, \mathrm{CFC}-113, \mathrm{HCFC}-22, \mathrm{CCl}_{4}$, $\mathrm{CH}_{3} \mathrm{CCl}_{3}, \mathrm{CH}_{3} \mathrm{Cl}$, and $\mathrm{CH}_{3} \mathrm{Br}$. The best estimates of the lifetimes inferred from observations are also listed for each species. In this study, for molecules that have a strong hydroxyl radical loss (e.g., $\mathrm{CH}_{4}$ ), the MZ3-EXP471 simulation gives the best result, followed by the MZ3-WA1b and MZ3-Op simulations. This would suggest the tropopsheric $\mathrm{OH}$ abundance is best represented in MOZART-3 when the EXP471 meteorological fields are used. For species whose loss is dependent on stratospheric photolysis and/or loss with $\mathrm{O}\left({ }^{1} \mathrm{D}\right)$, the MZ3-WA1b simulation give the best comparison to lifetimes inferred from observations, followed by MZ3-EXP471 and MZ3-Op. This result is consistent with the mean age of air being older in MZ3-WA1b simulation relative to the other two simulations. Using lifetimes analysis as a diagnostic for meteorological field performance should be considered as only a rough metric, since there is considerable uncertainty in the results inferred from observations.

[34] In Figure 6, the tropical time-height propagation of $\mathrm{H}_{2} \mathrm{O}$ in the equatorial region (averaged between $12^{\circ} \mathrm{S}$ and $12^{\circ} \mathrm{N}$ ) is shown. The MZ3-WA1b simulation has strong propagation of dry and wet regimes up to the midstratosphere. This propagation pattern is known as the $\mathrm{H}_{2} \mathrm{O}$ " tape recorder signal". The MZ3-WA1b wet phase of the tape recorder signal is too moist compared to observations. This has been discussed by Park et al. [2004] and Gettelman et al. [2004]. The MZ3-EXP471 and MZ3-Op simulations are too dry relative to observations based on the HALOE climatology and they do not have the correct seasonal evolution at the equatorial tropopause. The difference in the seasonal evolution of $\mathrm{H}_{2} \mathrm{O}$ can be related to the seasonal evolution of cold point temperatures (Figure $3 \mathrm{~b}$ ). In the MZ3-ECMWF simulations, the minimum in temperature at the cold point occurs in November and December. It is well known that the year 2000 cold point temperatures during November and December are colder than the climatological mean [Randel et al., 2004]. Therefore the dry phase of the tape recorder signal starts earlier than the UARS climatology in both MZ3-ECMWF simulations. The wet phase (near $100 \mathrm{hPa}$ ) of the tape recorder is similar to the HALOE

Table 2. Global Annual Average Photochemical Lifetime for Selected Species ${ }^{\text {a }}$

\begin{tabular}{lcccc}
\hline Species & $\begin{array}{c}\text { Inferred From } \\
\text { Observations }\end{array}$ & MZ3-Op & MZ3-EXP471 & MZ3-WA1b \\
\hline $\mathrm{CH}_{4}$ & $8.9^{\mathrm{b}}$ & 10.0 & 8.7 & 9.4 \\
$\mathrm{~N}_{2} \mathrm{O}$ & $120^{\mathrm{b}}$ & 110 & 113 & 114 \\
$\mathrm{CFC}-11$ & $45^{\mathrm{c}}$ & 42 & 50 & 56 \\
$\mathrm{CFC}-12$ & $100^{\mathrm{c}}$ & 81 & 86 & 93 \\
$\mathrm{CFC}-113$ & $85^{\mathrm{c}}$ & 73 & 79 & 85 \\
$\mathrm{HCFC}-22$ & $12.0^{\mathrm{b}}$ & 12.6 & 10.9 & 11.7 \\
$\mathrm{CCl}_{4}$ & $35^{\mathrm{d}}$ & 36.4 & 44.3 & 48.6 \\
$\mathrm{CH}_{3} \mathrm{CCl}$ & $5.0^{\mathrm{c}}$ & 5.3 & 4.7 & 5.1 \\
$\mathrm{CH}_{3} \mathrm{Cl}$ & $1.5^{\mathrm{c}}$ & 1.5 & 1.3 & 1.4 \\
$\mathrm{CH}_{3} \mathrm{Br}$ & $1.7^{\mathrm{e}}$ & 1.8 & 1.5 & 1.7 \\
\hline
\end{tabular}

${ }^{\mathrm{a}}$ Lifetimes are in years.

${ }^{\mathrm{b}}$ From Intergovernmental Panel on Climate Change [2001, Table 4.1]. For $\mathrm{CH}_{4}$, this includes reactions with $\mathrm{OH}$ and $\mathrm{O}\left({ }^{1} \mathrm{D}\right)$. It does not include soil sink term. For $\mathrm{N}_{2} \mathrm{O}$, this lifetime is the global mean atmospheric lifetime, not the perturbation lifetime.

${ }^{\mathrm{c}}$ From $W M O$ [2003, Table 1.6]. For $\mathrm{CH}_{3} \mathrm{Cl}$, this lifetime only includes reaction with $\mathrm{OH}$. Additional sinks (e.g., chlorine radicals in the marine boundary layer, soil uptake, or degradation in seawater) reduce this lifetime to 1.3 years.

${ }^{\mathrm{d}}$ From Happel and Roche [2003]. For $\mathrm{CCl}_{4}$ this includes only the atmospheric lifetime (i.e., does not includes ocean or soil uptake). Including these other sinks reduces the lifetime 20 years. The $\mathrm{CCl}_{4}$ atmospheric lifetime is based on Volk et al. [1997].

${ }^{\mathrm{e}}$ From Yvon-Lewis and Butler [1997]. For $\mathrm{CH}_{3} \mathrm{Br}$, this lifetime is due to in situ reactions only. It does not include additional sinks (e.g., ocean uptake), which would reduce the lifetime to 0.7 years. 

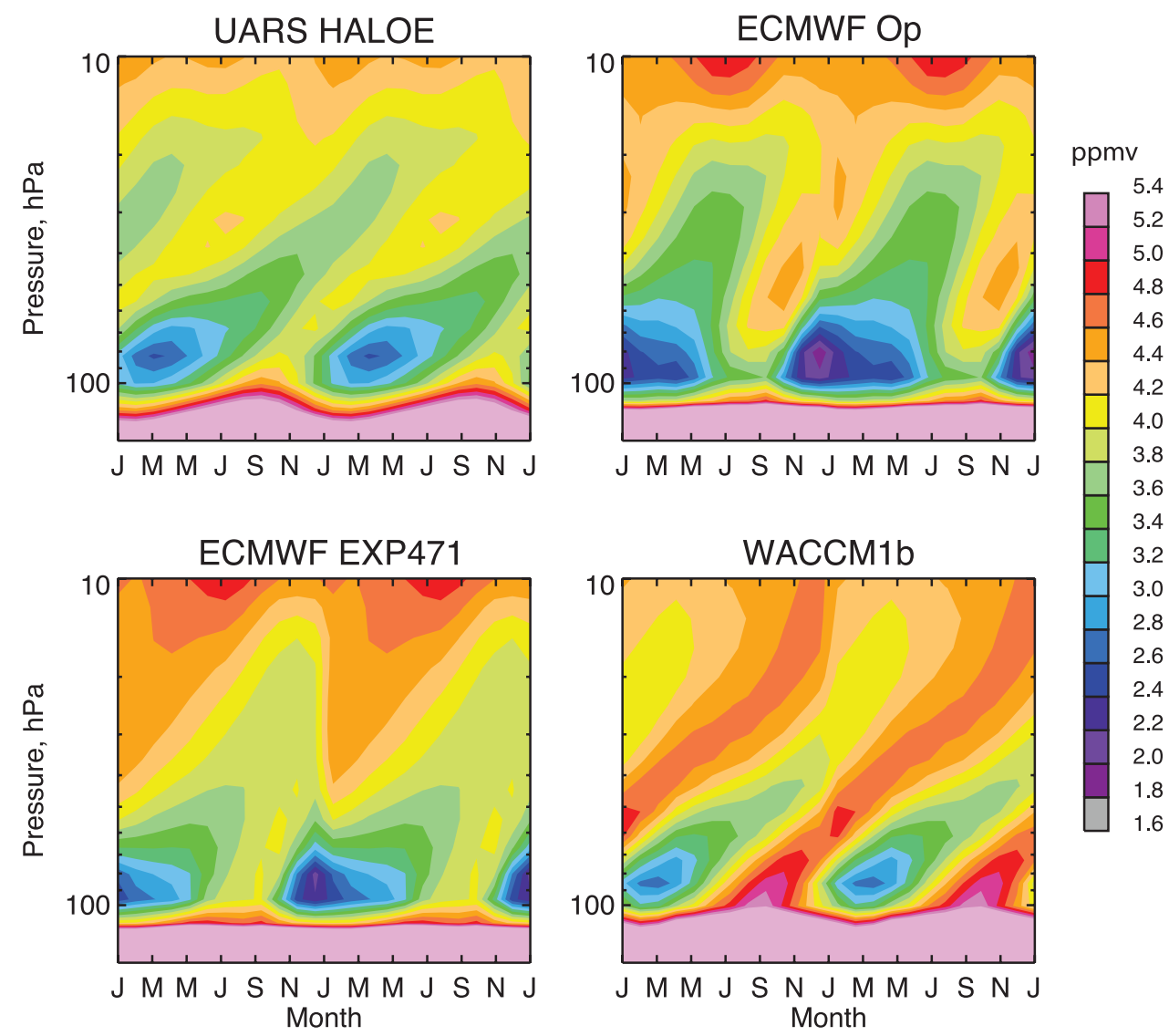

Figure 6. Height-time sections of water vapor volume mixing ratio derived in the equatorial region (averaged between $12^{\circ} \mathrm{S}$ and $12^{\circ} \mathrm{N}$ ). Observations are based on HALOE data. Two consecutive seasonal cycles are shown in each diagram.

climatology in the MZ3-ECMWF simulations. The dry and wet phases of the tape recorder signal also propagate too rapidly in the MZ3-ECMWF simulations. In Figure 7a, the phase lag for the dry phase of the tape recorder signal is shown for all three simulations and the UARS climatology (see Waugh and Hall [2002] for discussion of phase lag and model results). It takes about 4 months and 8 months to propagate the dry signal up to $20 \mathrm{hPa}$ in the MZ3-Op and
MZ3-EXP471 simulations, respectively. Observations suggest a period of 14 months. In the MZ3-WA1b simulation, the propagation timescale of the tape recorder signal to $20 \mathrm{hPa}$ is a little over one year, slightly less than observations would suggest. In Figure $7 \mathrm{~b}$, the attenuation of the $\mathrm{H}_{2} \mathrm{O}$ tape recorder signal is shown. Here the MZ3-EXP471 simulation is attenuated most rapidly between $100 \mathrm{hPa}$ and approximately $20 \mathrm{hPa}$ relative to the other simulations. The MZ3-WA1b simulation is attenuated slightly more than
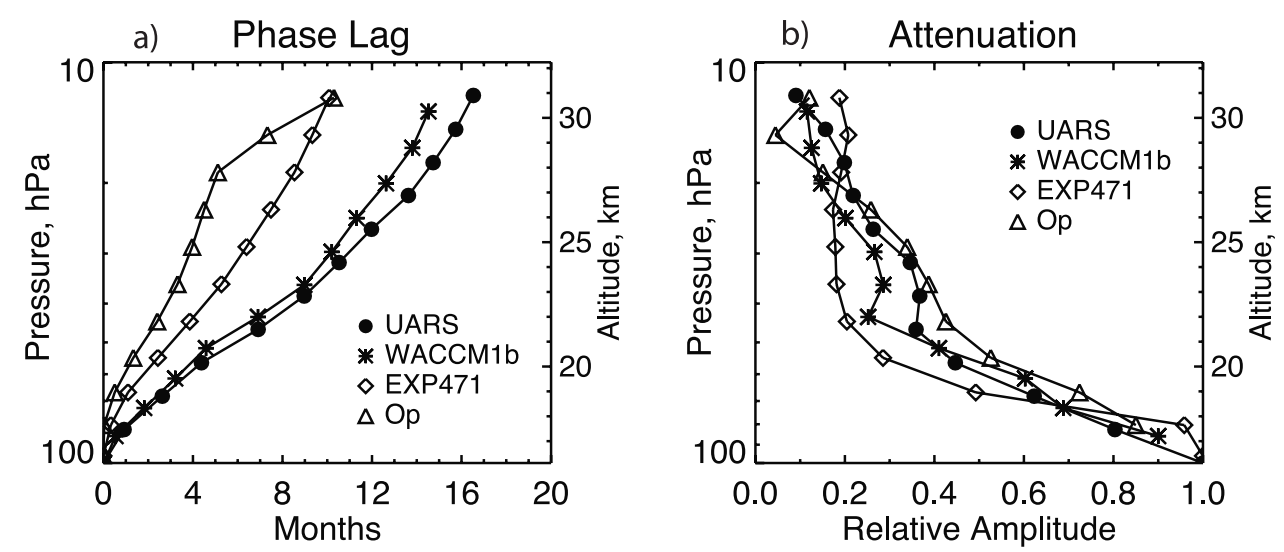

Figure 7. Vertical profiles of transport diagnostics for water vapor averaged between $12^{\circ} \mathrm{S}$ and $12^{\circ} \mathrm{N}$ latitude. (a) The phase lag of the dry phase of the vertically propagating $\mathrm{H}_{2} \mathrm{O}$ vapor abundance. (b) The attenuation of the $\mathrm{H}_{2} \mathrm{O}$ vapor abundance. The attenuation is forced to be unity at $100 \mathrm{hPa}$ for cases. 

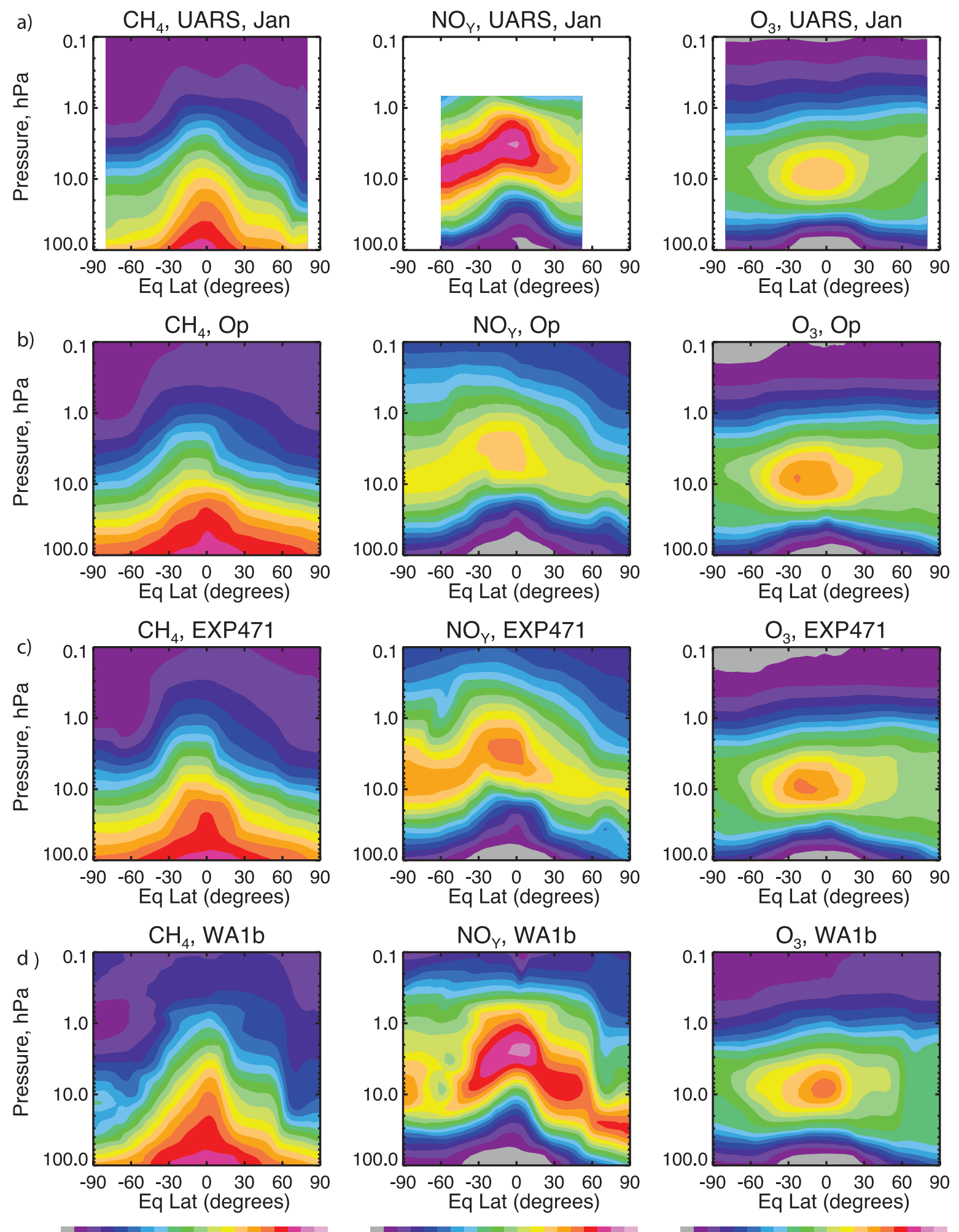

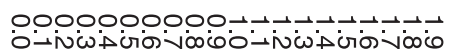
ppmv

०-กผ

\section{ppbv}

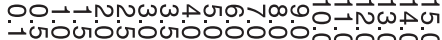

\section{ppmv}

Figure 8. Zonal mean latitude-altitude cross sections of $\mathrm{CH}_{4}, \mathrm{NO}_{y}$, and $\mathrm{O}_{3}$ in January. Observations are based on UARS climatology. Both observations and model results have been mapped to an equivalent latitude pressure grid. 

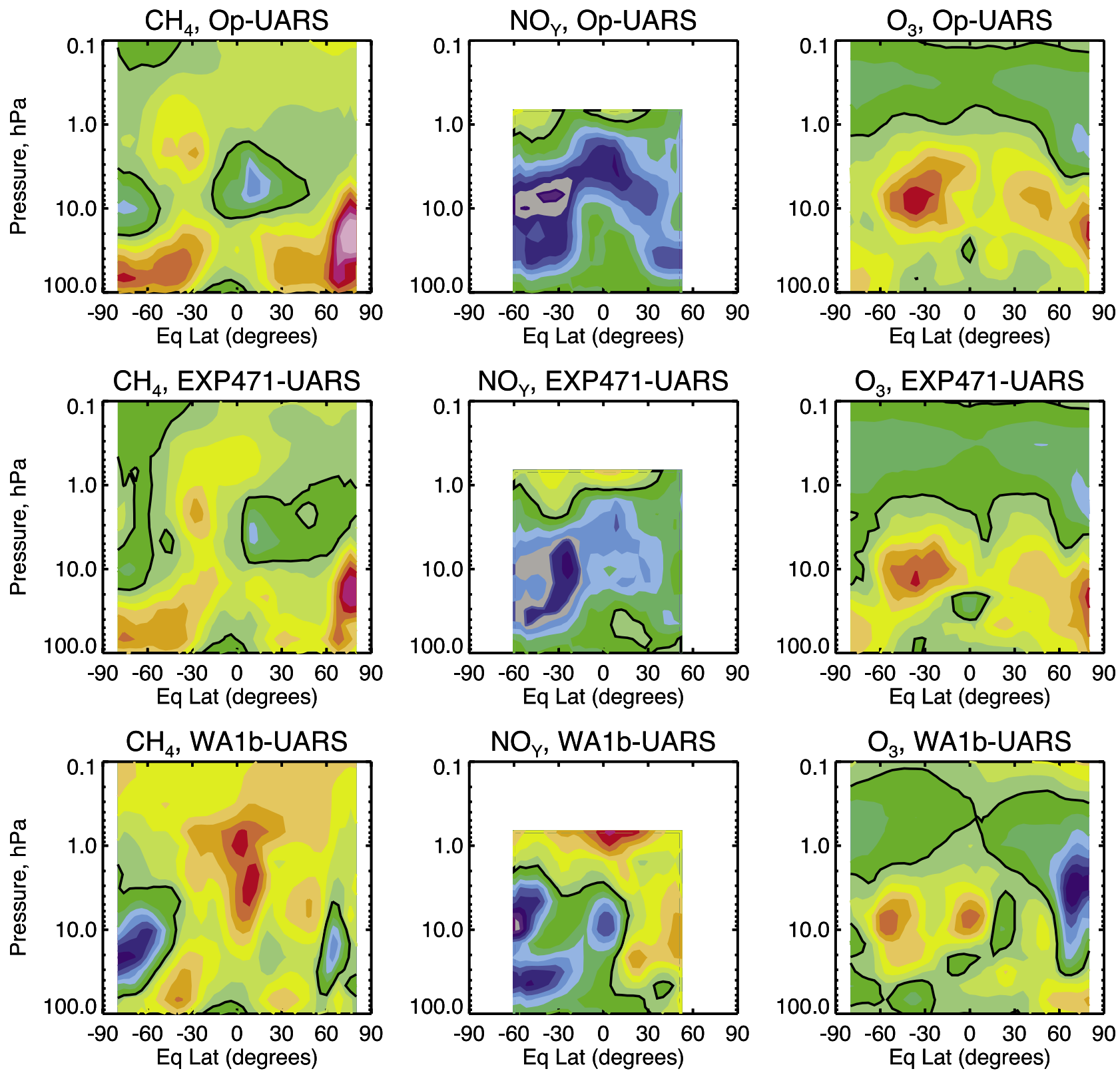

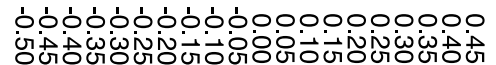

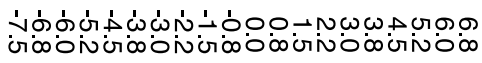
ppbv

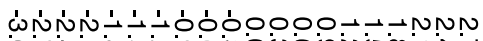

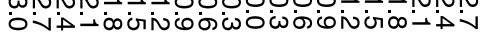

\section{ppmv}

Figure 9. Same as Figure 8, except latitude-altitude cross sections of $\mathrm{CH}_{4}, \mathrm{NO}_{y}$, and $\mathrm{O}_{3}$ are differenced to the UARS climatology shown in Figure 8.

observations. The MZ3-Op simulation is attenuated less than observations.

[35] A simple method for assessing the representation of transport processes in the model is to analyze the distribution of relatively inert tracers. In Figure 8 , we show as a function of latitude and height the zonally averaged mixing ratio of $\mathrm{CH}_{4}, \mathrm{NO}_{y}$, and $\mathrm{O}_{3}$ between $100 \mathrm{hPa}$ and $0.1 \mathrm{hPa}$ in January. Figure 8 a shows values measured by the Upper Atmosphere Research Satellite (UARS), Figures 8b-8d represent the distributions calculated when the model is driven by the Op, EXP471, and WACCM1b winds and temperatures, respectively. In Figure 9, the difference in $\mathrm{CH}_{4}, \mathrm{NO}_{y}$, and $\mathrm{O}_{3}$ relative to the UARS climatology is shown for the three simulations. The differences between the distributions highlight the influence of uncertainties in the three-dimensional transport on the calculated tracer distributions. The observational climatology can help in 
evaluating the model results and, specifically, the simulated transport.

[36] When comparing the fields of $\mathrm{CH}_{4}$ obtained for the three sets of dynamical meteorological fields, it immediately appears that the transport generated by the Op analyzed winds leads to meridional tracer distributions that are somewhat "smoother" in latitude than when the winds produced by either EXP471 or WACCM1b are adopted. This is also seen in the difference plot for the Op case, which has larger $\mathrm{CH}_{4}$ values in the extratropics. There is also less $\mathrm{CH}_{4}$ in the deep tropics between $10 \mathrm{hPa}$ and $5 \mathrm{hPa}$. This is consistent with less $\mathrm{CH}_{4}$ reaching this altitude because of excessive horizontal transport below this altitude range. In the WACCM1b case, the dynamical barriers separating tropical from midlatitude air, and midlatitude from polar air are more pronounced, in particular in the winter Northern Hemisphere. In January (Figure 8), for example, a clear "surf zone" located between the dynamical barriers near $15^{\circ} \mathrm{N}$ and $50^{\circ} \mathrm{N}$ can be seen in the tracer distributions only when the WACCM1b winds are used. This feature is also clearly visible in the observed zonal monthly mean $\mathrm{CH}_{4}$ distribution, although it is more pronounced in the MZ3-WA1b simulation. In the MZ3-WA1b case, the upward branch of the Brewer-Dobson circulation seems to be very narrow around the equator, and the associated vertical flow of air appears to be stronger, or the horizontal mixing weaker, than suggested by the observations of tracers like $\mathrm{CH}_{4}$. This will be discussed in more detail below. In the tropical middle stratosphere, the absolute mixing ratio of $\mathrm{CH}_{4}$ calculated with EXP471 fields is closer to the observed values than when calculated with WACCM1b meteorology. In the extratropics, the observed mixing ratio of $\mathrm{CH}_{4}$ in the lower stratosphere $(100-50 \mathrm{hPa})$ is best reproduced in January when the model is driven by WACCM1b meteorology. However, in the MZ3-WA1b simulation polar $\mathrm{CH}_{4}$ volume mixing ratios in Northern Hemisphere winter are significantly lower than suggested by the UARS climatology. This feature in the MZ3-WA1b simulation is indicative of strong descent within the polar vortex and/or less mixing with midlatitude air. However, Northern Hemisphere polar descent is known to have strong interannual variability; therefore any agreement (or lack of) with respect to an observational climatology is not particularly revealing. Conversely, the high extratropoical $\mathrm{CH}_{4}$ concentration values produced by the MZ3-Op and MZ3EXP471 cases are suggestive of too rapid meridional transport of air masses from the tropics. The circulation and transport of tracers appear therefore to be very different in the three model simulations, and the differences are broadly consistent with the calculated mean age of air. In the MZ3-WA1b case, the mean age of air (Figures 4 and 5) that reaches the polar lower stratosphere during winter is considerably older ( 4.5 years at $20 \mathrm{~km}$ ) than in the Op case ( 2 years at $20 \mathrm{~km}$ ), which suggests that the meridional exchanges derived from this latter data set are substantially faster than in the former case. This conclusion regarding the MZ3-Op meteorological fields is consistent with the findings of van Noije et al. [2004].

[37] In Figures 8 (center) and 9 (center), total inorganic nitrogen $\left(\mathrm{NO}_{y}\right)$ is shown. There is good agreement between the peak mixing ratio of $\mathrm{NO}_{y}\left(\mathrm{NO}+\mathrm{NO}_{2}+2 * \mathrm{~N}_{2} \mathrm{O}_{5}+\right.$ $\mathrm{HNO}_{3}$ ) for the MZ3-WA1b simulation (approximately
18 ppbv), and the peak $\mathrm{NO}_{y}\left(\mathrm{NO}_{\mathrm{ss}}+\mathrm{NO}_{2 \mathrm{ss}}+\mathrm{HNO}_{3}\right)$ derived from UARS observations. This approach of comparing model $\mathrm{NO}_{y}$ (as defined above) with $\mathrm{NO}_{y}$ derived from observations of $\mathrm{HNO}_{3}$ summed with $\mathrm{NO}$ and $\mathrm{NO}_{2}$ sunset data follows the recommendations of Park et al. [1999]. In contrast, the peak $\mathrm{NO}_{y}$ abundance is approximately 14 ppbv and 16 ppbv for the MZ3-Op and MZ3EXP471 simulations respectively. The MZ3-Op simulation does a poor job of representing the $\mathrm{NO}_{y}$ vertical and horizontal structure relative to the UARS climatology. The $\mathrm{NO}_{y}$ isopleths are too flat relative to observations, consistent with the mean age-of-air results shown in Figure 4. At pressures equal to $10 \mathrm{hPa}$ and less (lower in altitude), all three simulations underestimate $\mathrm{NO}_{y}$ (and $\mathrm{NO}_{x}$, not shown). This affects the $\mathrm{O}_{3}$ distributions discussed below.

[38] In the case of $\mathrm{O}_{3}$, the calculated latitude-height distributions for the month of January shown in Figure 8 (and the difference distributions in Figure 9) show noticeable differences from the UARS climatology. The maximum $\mathrm{O}_{3}$ abundance in all model simulations in the tropical stratosphere near $10 \mathrm{hPa}$ is approximately $1-2$ ppbv higher than the UARS climatology. The $\mathrm{O}_{3}$ abundance is also too high in the middle stratosphere extratropics. The high bias in model $\mathrm{O}_{3}$ is consistent with the low bias in $\mathrm{NO}_{y}$. One can clearly see this when comparing Figures 8(middle) and 8(right) with (Figures 9(middle) and 9(right).

[39] It is well known that the main stratospheric production of $\mathrm{NO}_{y}$ is from the reaction of $\mathrm{O}\left({ }^{1} \mathrm{D}\right)$ with nitrous oxide $\left(\mathrm{N}_{2} \mathrm{O}\right)$ forming two nitric oxide $(\mathrm{NO})$ molecules. In Figure $10 \mathrm{a}-10 \mathrm{c}$, the annual average production rate of $\mathrm{NO}_{y}$ is shown for cases $1-3$. There clearly is a progression of increasing $\mathrm{NO}_{y}$ production rate from MZ3-Op to MZ3EXP471 to MZ3-WAb. The production rate of $\mathrm{NO}_{y}$ is primarily influenced by the transport of $\mathrm{N}_{2} \mathrm{O}$ (not shown, but similar to the $\mathrm{CH}_{4}$ distribution shown in Figure 8). For MZ3-Op simulation, since less $\mathrm{N}_{2} \mathrm{O}$ reaches the middle stratosphere, this has the net effect of producing too little $\mathrm{NO}_{y}$ globally less than $1 \mathrm{hPa}$ (lower in altitude). The altitude where the peak $\mathrm{NO}_{y}$ production rate is a maximum also shifts upward when going from MZ3-Op to MZ3EXP471 to MZ3-WA1b, where the peak $\mathrm{NO}_{y}$ production rate is at approximately $15 \mathrm{hPa}$ in MZ3-Op, at $12 \mathrm{hPa}$ in MZ3-EXP471, and at $8 \mathrm{hPa}$ for MZ3-WA1b. The tropical abundance of $\mathrm{NO}_{y}$ relative to the $\mathrm{N}_{2} \mathrm{O}$ abundance is shown in Figure 10d. The $\mathrm{N}_{2} \mathrm{O}$ abundance can be considered an altitude coordinate, with altitude increasing with decreasing abundance of $\mathrm{N}_{2} \mathrm{O}$. As the $\mathrm{N}_{2} \mathrm{O}$ abundance is reduced, more $\mathrm{NO}_{y}$ is formed, at least up to the peak of the $\mathrm{NO}_{y}$ versus $\mathrm{N}_{2} \mathrm{O}$ curve. At some point, $\mathrm{NO}_{y}$ loss becomes the dominant processes and $\mathrm{NO}_{y}$ decreases with decreasing $\mathrm{N}_{2} \mathrm{O}$. What is clear from Figure 10d is that the $\mathrm{N}_{2} \mathrm{O}$ altitude coordinate is not consistent across simulations, that is, the transport processes that control $\mathrm{N}_{2} \mathrm{O}$ are very different and the rate of oxidation of $\mathrm{N}_{2} \mathrm{O}$ to $\mathrm{NO}_{y}$ varies considerable among the simulations considered in this paper.

[40] In Figure 11, the Transformed Eulerian Mean (TEM) vertical velocity is shown for four seasons, averaged between $20^{\circ} \mathrm{S}$ and $20^{\circ} \mathrm{N}$ latitudes (see Brasseur and Solomon [2005, and the references therein] for discussions of the TEM velocities). In this figure, the derived TEM vertical velocities are fairly consistent amongst the three simulations in the $100 \mathrm{hPa}$ to $50 \mathrm{hPa}$ altitude region; however, the MZ3- 

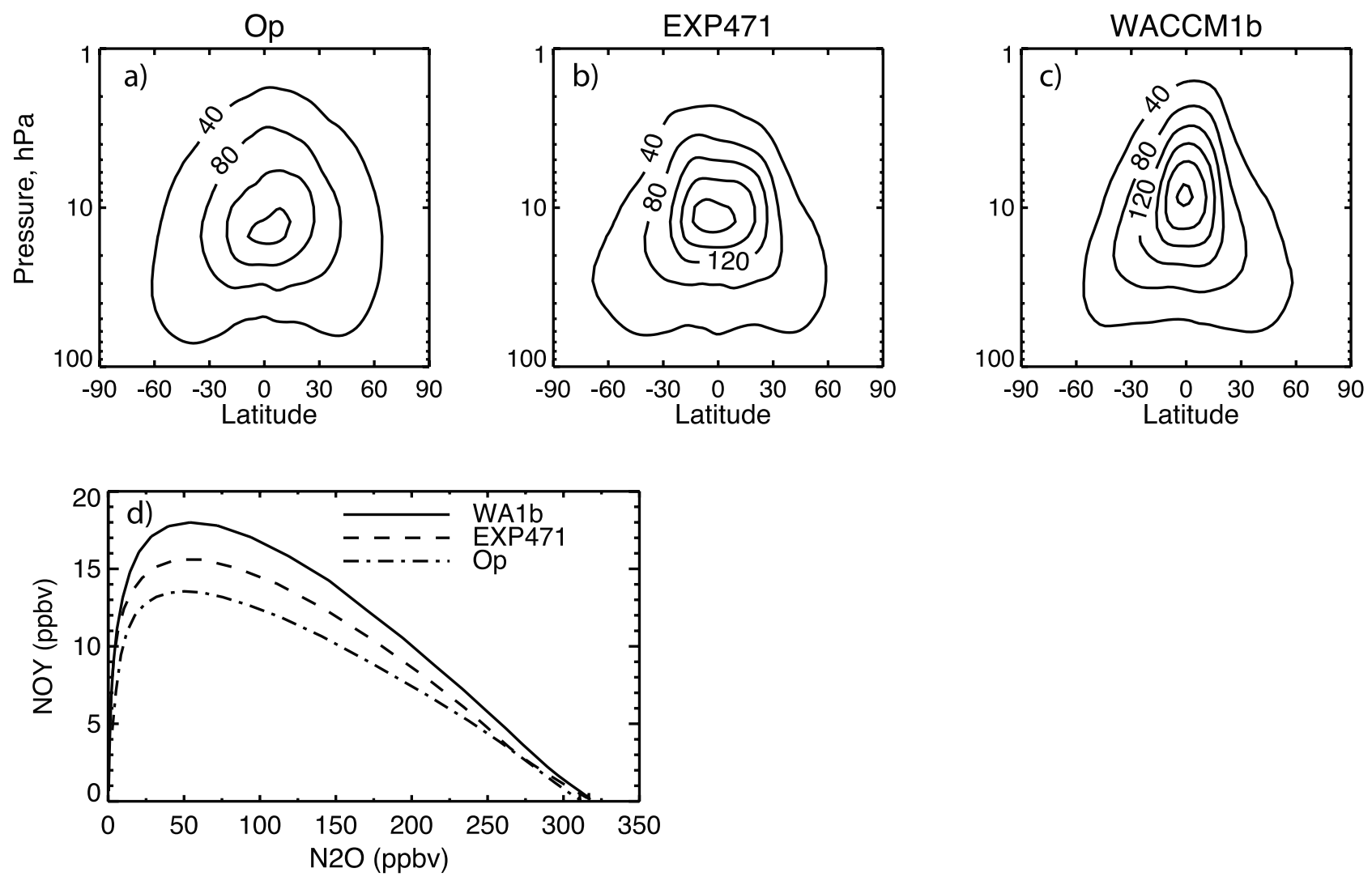

Figure 10. (a)-(c) Zonal mean latitude-altitude cross section of $\mathrm{NO}_{y}$ production rate in units of molecule $\mathrm{cm}^{-3} \mathrm{~s}^{-1}$. (d) Correlation of $\mathrm{NO}_{y}$ with $\mathrm{N}_{2} \mathrm{O}$ concentration averaged between $20^{\circ} \mathrm{S}$ and $20^{\circ} \mathrm{N}$ latitude.

WA1b simulation departs from the other two simulations near $20 \mathrm{hPa}$. At lower pressures (higher altitude), the MZ3WA1b vertical velocities can be up to a factor of two greater. This is especially true during the equinox seasons (MAM and SON). The larger tropical TEM vertical velocity in the $20 \mathrm{hPa}$ to $5 \mathrm{hPa}$ region in the MZ3-WA1b simulation is consistent with more rapid vertical transport of $\mathrm{N}_{2} \mathrm{O}$ and, as a consequence, an $\mathrm{NO}_{y}$ production region located at higher altitude than in the two ECMWF simulations.

[41] We will now investigate in more detail the processes responsible for the differences in the latitudinal and temporal evolution of ozone near the $10 \mathrm{hPa}$ ozone peak. In Figure 12a, the $\mathrm{O}_{3}$ time-latitude distribution is shown near the stratospheric $\mathrm{O}_{3}$ peak (near $10 \mathrm{hPa}$ ) for the three model simulations. The corresponding UARS climatology time-latitude distribution is shown in Figure 13. The UARS climatology shows the maximum in $\mathrm{O}_{3}$ at the spring and fall equinoxes with values approaching 10.5 ppmv. The MZ3-WA1b simulation time-latitude peak $\mathrm{O}_{3}$ distributions are centered on the equator. The MZ3-ECMWF simulations time-latitude peak $\mathrm{O}_{3}$ distributions are more consistent with the UARS Climatology; however, the absolute magnitude of $\mathrm{O}_{3}$ is too high. Solomon et al. [1985] showed that near $10 \mathrm{hPa}$ in the tropics $\mathrm{O}_{3}$ is close to photochemical equilibrium (lifetime with respect to total chemical loss is approximately 10 days) and that the $\mathrm{NO}_{x}$ catalytic cycle is the main odd oxygen loss process in this region.

[42] In Figure 12b, the time-latitude distribution of $\mathrm{NO}_{y}$ is shown for the three model simulations (near $10 \mathrm{hPa}$ ). The corresponding $\mathrm{NO}_{y}$ UARS climatology is shown in
Figure 13. The MZ3-WA1b $\mathrm{NO}_{y}$ time-latitude minima are also centered on the equator and significantly underestimate $\mathrm{NO}_{y}$ by $\sim 4-5$ ppbv relative to the UARS climatology. The MZ3-ECMWF $\mathrm{NO}_{y}$ time-latitude minima values are more similar to the UARS climatology, but also significantly underestimate the $\mathrm{NO}_{y}$ abundance $(\sim 3-4 \mathrm{ppbv})$. For the MZ3-WA1b simulation, the tropical, $20 \mathrm{hPa}$ to $10 \mathrm{hPa}$ region is too isolated (e.g., see $\mathrm{CH}_{4}$ distributions in Figures 8 and 9), allowing low $\mathrm{NO}_{y}$ values to be transported from the lower stratosphere to the midstratosphere, without mixing in higher extratropical $\mathrm{NO}_{y}$ air. This is clearly seen in the MZ3-WA1b latitude-height $\mathrm{NO}_{y}$ distributions (Figure 8). The MZ3-EXP471 simulation in the tropical stratosphere near $10 \mathrm{hPa}$ is less isolated relative to the MZ3WA1b simulation as shown by the $\mathrm{CH}_{4}$ isopleths (Figures 8 and 9); and there is additional abundance of $\mathrm{NO}_{y}$ in the $10 \mathrm{hPa}$ region in the MZ3-EXP471 case relative to the MZ3-WA1b case. The MZ3-Op simulation also underestimates the $\mathrm{NO}_{y}$ abundance relative to the UARS climatology, but not as much as the MZ3-EXP471 and MZ3-WA1b simulations. Nonetheless, in all three simulations, the $\mathrm{NO}_{y}$ abundance at the equatorial $\mathrm{O}_{3}$ maximum is significantly underestimated.

[43] In Figure 12c, the time-dependent TEM vertical velocities are shown between $50^{\circ} \mathrm{S}$ and $50^{\circ} \mathrm{N}$ latitudes. One can clearly see that the vertical velocities for all three simulations evolve in a manner consistent with $\mathrm{NO}_{y}$ distributions in this figure. For example, in the MZ3-Op simulation, $\mathrm{NO}_{y}$ is high where the TEM vertical velocities are downward (negative in Figure 12), bringing higher 
a)
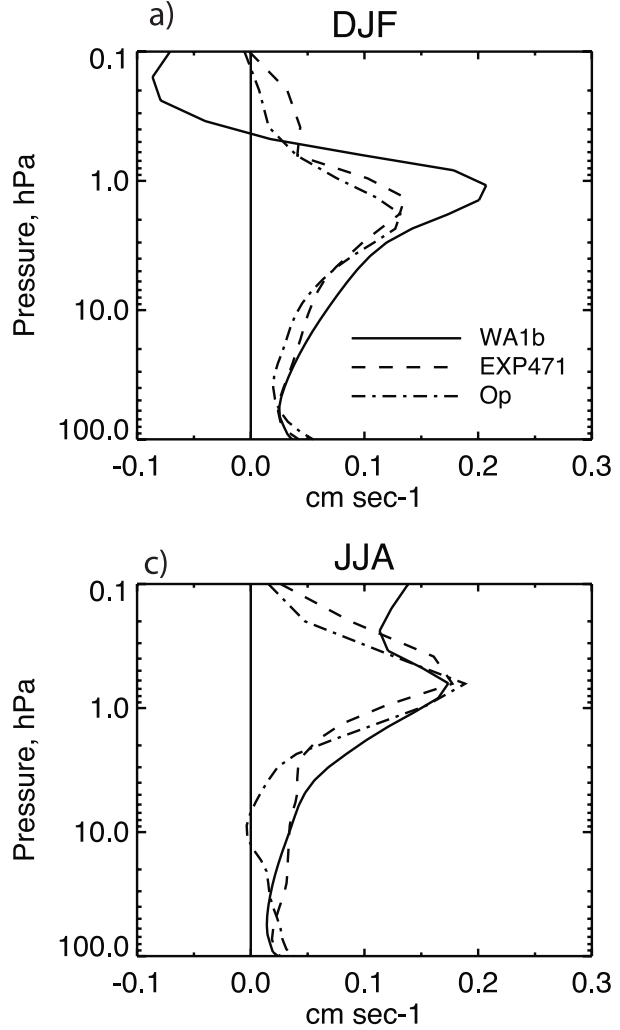

b)
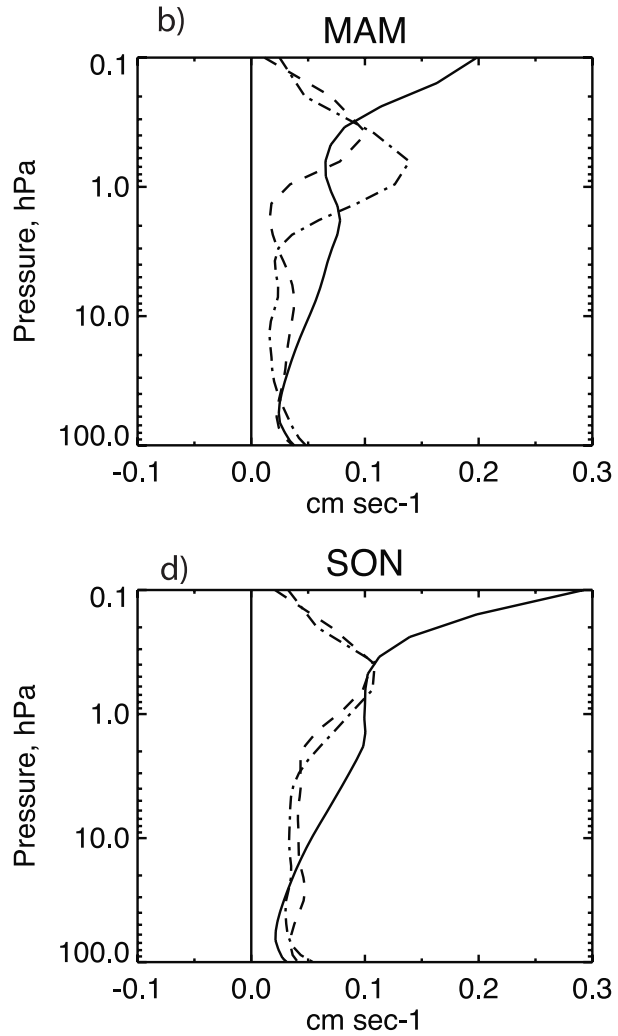

Figure 11. Vertical profiles of seasonal TEM vertical velocities $\left(\mathrm{cm} \mathrm{s}^{-1}\right)$ for seasons (a) DecemberJanuary-February (DJF), (b) March-April-May (MAM), (c) June-July-August (JJA), and (d) September-October-November (SON).

abundances of $\mathrm{NO}_{y}$ from above to the $10 \mathrm{hPa}$ level. When $\mathrm{NO}_{y}$ abundances are higher, $\mathrm{O}_{3}$ abundances are lower, consistent with increased catalytic odd oxygen loss from the $\mathrm{NO}_{x}$ family. The MZ3-EXP471 simulation also shows a similar relationship between the evolution of the TEM vertical velocities and $\mathrm{NO}_{y}$ abundances. However, it should be pointed out that the MZ3-EXP471 TEM vertical velocities tend to be less variable (i.e., less "noisy") than the MZ3-Op values. The MZ3-WA1b simulation also shows a strong correlation between the TEM vertical velocities and $\mathrm{NO}_{y}$ abundances. However, the MZ3-WA1b TEM vertical velocities are larger (as shown in Figure 11) and the temporal distribution of the vertical TEM velocities is mostly upward in the tropics.

[44] In Figure 12d, the $10 \mathrm{hPa}$ latitudinal and temporal evolution of the TEM horizontal velocities are shown. Here a negative velocity designates flow toward the south; a positive velocity is designates flow toward the north. It is clear from this figure that the MZ3-WA1b simulation has the smallest TEM meridional magnitudes and temporal gradients. This is consistent with the high $\mathrm{CH}_{4}$ (Figure 8) and low $\mathrm{NO}_{y}$ abundances in the MZ3-WA1b simulation being isolated in the deep tropics.

[45] The interesting behavior of the $\mathrm{NO}_{y}$ distribution in the MZ3-WA1b simulation relative to the MZ3-ECMWF simulations can be partially reconciled if one remembers the WACCM1b meteorological fields do not resolve a QBO structure in the zonal winds (Figure 1). The secondary meridional circulation that accompanies the QBO is downward in the region of westerly shear. This will tend to transport high $\mathrm{NO}_{y}$ from above and consequently reduce ozone. This effect has been discussed recently by Tian et al. [2006] who used a chemistry climate model that internally generated a QBO. One of the main conclusions from this study was that variations in $\mathrm{NO}_{y}$ (and $\mathrm{NO}_{x}$ ) induced by the secondary circulation of the QBO were responsible for modulating $\mathrm{O}_{3}$ in the $10 \mathrm{hPa}$ region of the tropical stratosphere. We have obtained similar results with a fully interactive version of WACCM, run with and without an imposed QBO (not shown). The simulation without a QBO was very similar to the MZ3-WA1b simulation in this paper, whereas the simulation that included a QBO resembled the MZ3-ECMWF results, especially for those years that had the same phase of the QBO as the year 2000 ECMWF meteorological fields.

\subsection{Column Ozone and Polar Processes}

[46] An examination of the behavior of tracers at high latitudes in both hemispheres provides additional information on the ability of the WACCM1b and ECMWF wind and temperature fields to properly simulate the transport of long-lived species. In the case of polar $\mathrm{H}_{2} \mathrm{O}$ (Figure 14), the model simulations are compared with POAM III observations from the year 2000 and a POAM III climatology (1998-2005 average). In Figure 14, model results have been sampled at the POAM III measurement locations. The POAM III $\mathrm{H}_{2} \mathrm{O}$ in 2000 is shown for comparison to the MZ3-ECMWF simulations, while the MZ3-WA1b simulation is not specific to any 1 year and is more appropriately compared to the POAM III climatology. In the Arctic, the 

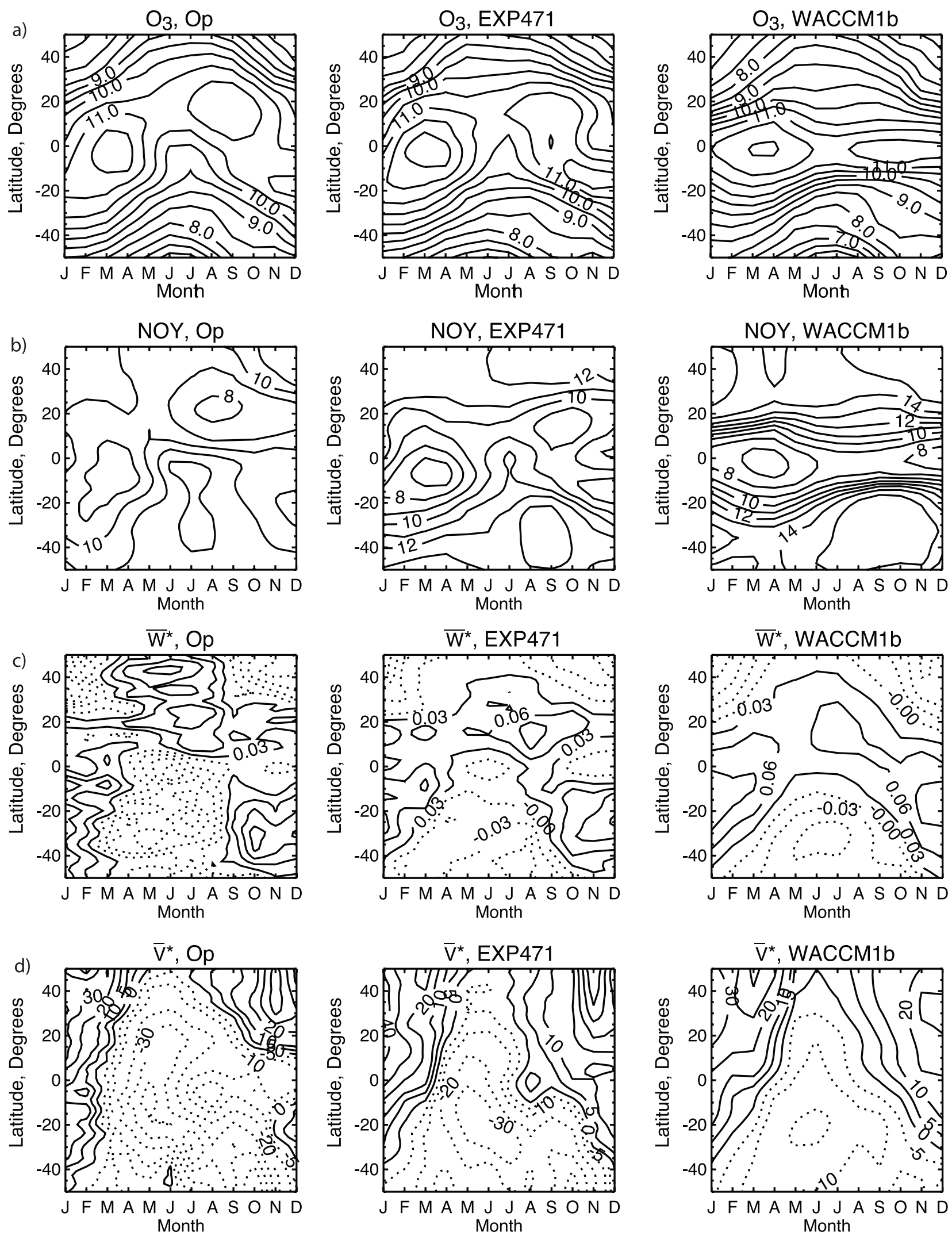

Figure 12. Latitude-time distributions at $10 \mathrm{hPa}$ for $\mathrm{O}_{3}$ (ppmv), $\mathrm{NO}_{y}$ (ppbv), TEM vertical velocity $\left(\mathrm{cm} \mathrm{s}^{-1}\right.$ ), and TEM meridional velocities $\left(\mathrm{cm} \mathrm{s}^{-1}\right.$ ): (left) MZ3-Op, (middle) MZ3-EXP471, and (right) MZ3-WA1b. 

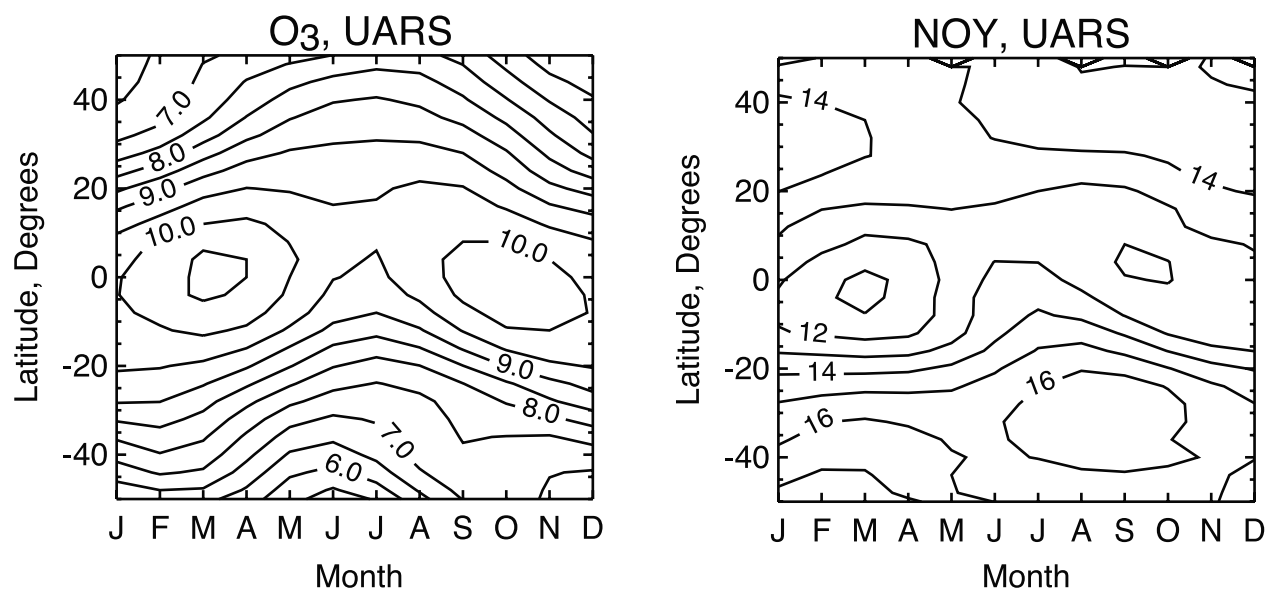

Figure 13. Zonal mean latitude-time sections of ozone (ppmv) and $\mathrm{NO}_{y}$ (ppbv) at $10 \mathrm{hPa}$. Observations are based on UARS HALOE and CLAES data. See text for details.

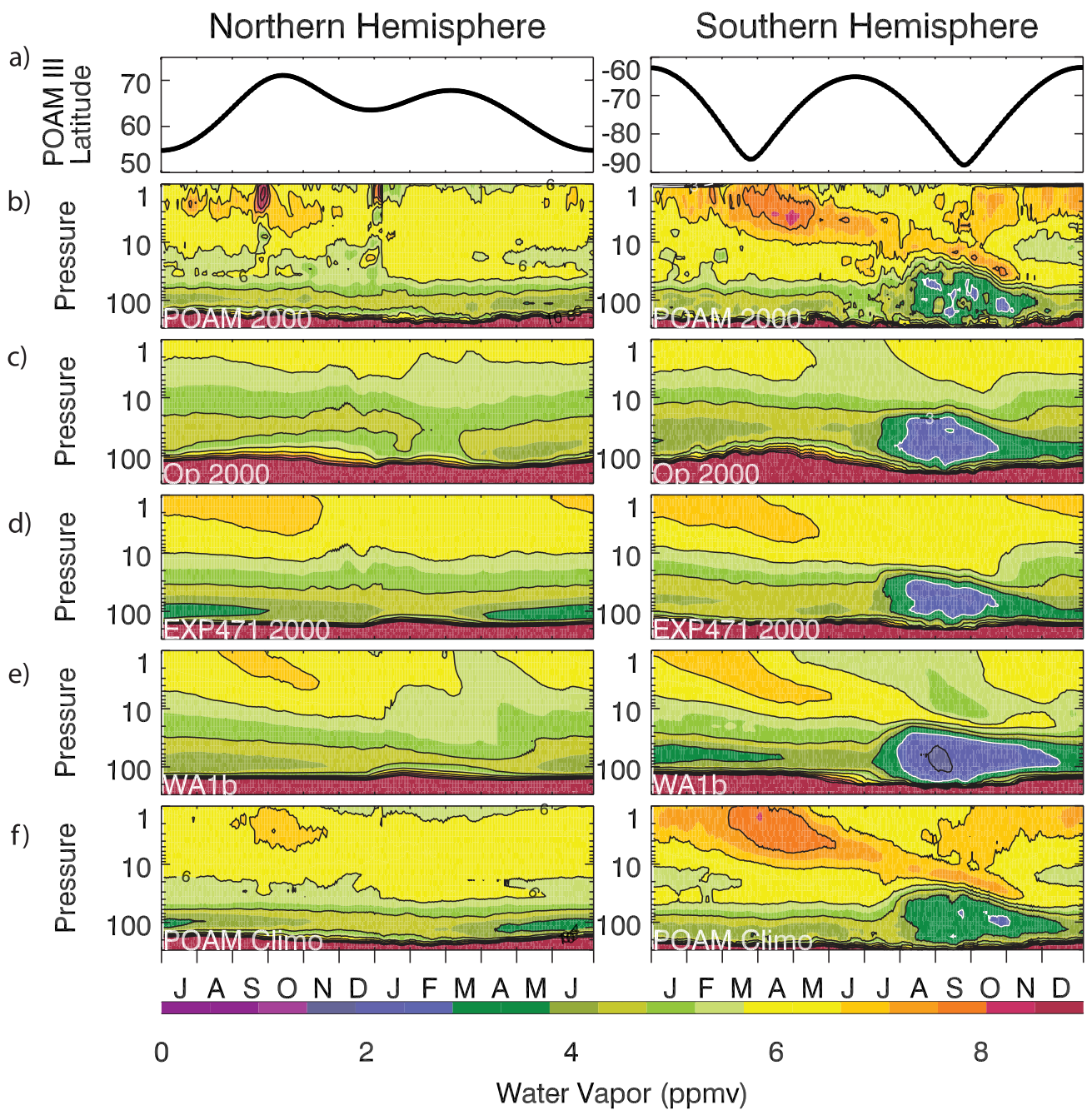

Figure 14. Height-time cross sections of water vapor volume mixing ratio at the POAM III measurement locations. POAM III water vapor is shown for year 2000 (Figure 14b) and climatology made of years 1998-2005 (Figures 14c-14f) from the model simulations (c) MZ3-Op, (d) MZ3-EXP471, and (e) MZ3-WA1b for high-latitude (left) Northern Hemisphere and (right) high-latitude Southern Hemisphere data and model results. 

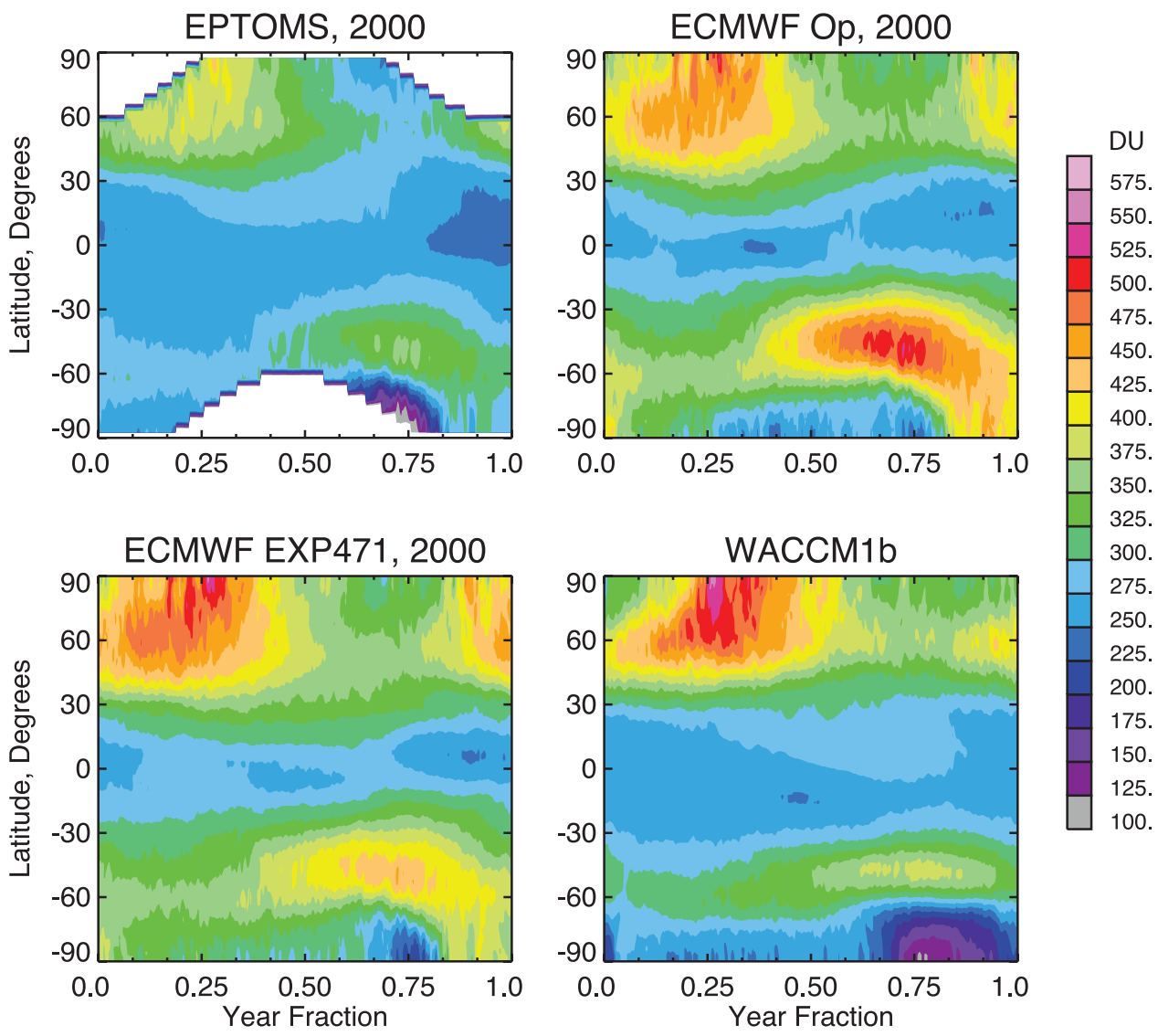

Figure 15. Latitude-time sections for total column ozone in Dobson Units (DU). EP/TOMS observations, MZ3-Op, and MZ3-EXP471 are for year 2000. MZ3-WA1b results are from a presentday atmosphere, consistent with source gas loading of year 1999, but do not represent a particular year.

mixing ratio of $\mathrm{H}_{2} \mathrm{O}$ does not change substantially during the year along the measurement track of POAM III at any altitude. The weak maximum of near 7 ppmv in the POAM III $\mathrm{H}_{2} \mathrm{O}$ climatology between $1 \mathrm{hPa}$ and $5 \mathrm{hPa}$ from August to November is not captured when the Op winds are adopted, but is reproduced when the EXP471 and WACCM1b fields are used. The $\mathrm{H}_{2} \mathrm{O}$ minimum observed near $100 \mathrm{hPa}$ from March to August in the Northern Hemisphere in the POAM III climatology is not low enough in the MZ3-WA1b or the MZ3-Op simulation, but is better simulated when adopting ECMWF EXP471 meteorological fields. Overall, the MZ3-EXP471 simulation of Arctic $\mathrm{H}_{2} \mathrm{O}$ shows the best agreement with the POAM III climatology. In the Antarctic, the descent of high $\mathrm{H}_{2} \mathrm{O}$ volume mixing ratios $(6-8 \mathrm{ppmv})$ from the stratopause to $10 \mathrm{hPa}$ between January and June is reproduced in both the MZ3-WA1b and MZ3-EXP471 simulations, but the model $\mathrm{H}_{2} \mathrm{O}$ volume mixing ratios are smaller than in POAM III. The MZ3-Op simulation does a poor job of representing this feature. All model simulations produce realistic dehydration in the Southern Hemisphere lower stratosphere in spring, however, the MZ3-WA1b dehydration is more severe and extends higher in altitude than in the MZ3-ECMWF cases and in the POAM III observations.

[47] It is important to assess how the dynamical fields affect the seasonal evolution and latitudinal distribution of the total ozone column, and specifically the formation and dissipation of the springtime $\mathrm{O}_{3}$ hole in Antarctica. Here, the model simulations will be compared with data provided by the EP/TOMS instrument for the year 2000. The general patterns derived by the model (Figure 15) for the three meteorological simulations are relatively similar, and characterized by low tropical values, maximum values during spring in the Arctic and near $50^{\circ} \mathrm{S}$, and minimum values during springtime in the Antarctic. At most locations, the magnitude of the column calculated with the WACCM1b meteorological fields is, however, in better agreement with the observations than the values calculated with the Op and EXP471 meteorological fields. The MZ3-WA1b does an adequate job representing tropical total column ozone. In the MZ3-Op and MZ3-EXP471 simulations, the tropical total column ozone is approximately 25 DU higher (10\%) than observed.

[48] The Southern Hemisphere $\mathrm{O}_{3}$ in the polar lower stratosphere is shown in Figure 16. Here, the model simulations are sampled at the POAM III measurement locations and daily results are shown for three different potential temperature surfaces: $400 \mathrm{~K}(\sim 15 \mathrm{~km}) ; 450 \mathrm{~K}(\sim 18 \mathrm{~km})$; and $500 \mathrm{~K}(\sim 20 \mathrm{~km})$. Since air motions are nearly isentropic in the lower stratosphere, it is useful to examine the evolution of ozone using this vertical coordinate. The solid black line is for POAM III year 2000 (for comparison to the ECMWF runs). The solid gray line is the average for the entire POAM III data record (for comparison to the 

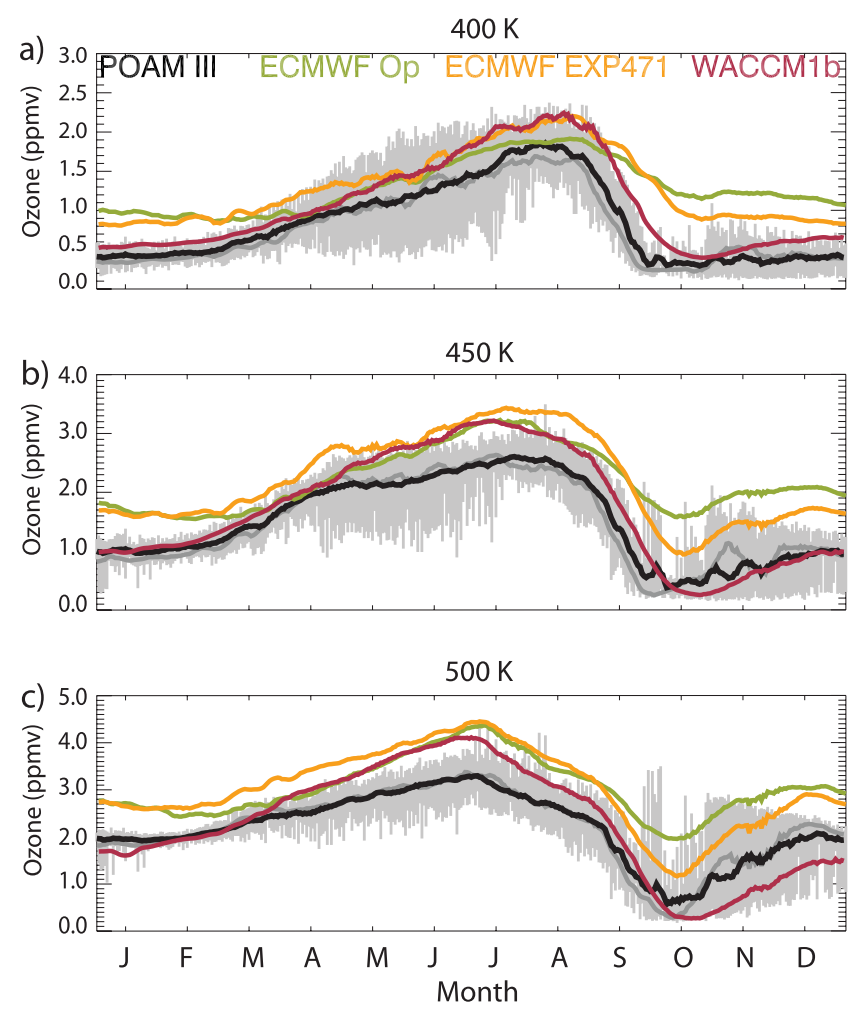

Figure 16. Time evolution of ozone volume mixing ratio at the POAM III measurement locations: (a) $400 \mathrm{~K}$, (b) $450 \mathrm{~K}$, and (c) $500 \mathrm{~K}$. Solid black line is for POAM II data for year 2000. Green line is for MZ3-Op, gold line is for MZ3-EXP471, and red line is for MZ3-WA1b. Gray line is the mean of all POAM III ozone observations between 1998 and 2005. The light gray shaded region in the background shows the range of all POAM III observations.

WACCM1b run). The light gray shading in the background represents the range of all POAM III observations. The green, orange, and red lines are for MZ3-Op, MZ3EXP471, and MZ3-WA1b, respectively. The MZ3-WA1b simulation best represents the local $\mathrm{O}_{3}$ evolution; however, the total ozone change from July through October is greater than observations would suggest. That is, at 500 $\mathrm{K}$ the model tends to start with higher $\mathrm{O}_{3}$ in July than observations, and ends up with a lower amount in October. The reason for this is not understood. Southern Hemisphere $\mathrm{O}_{3}$ depletion is much better represented in the MZ3-EXP471 simulation than in the MZ3-Op case. The total amount of MZ3-EXP471 Southern Hemisphere $\mathrm{O}_{3}$ depletion from July to October, on the $450 \mathrm{~K}$ and $500 \mathrm{~K}$ potential temperature surfaces, is similar to both the MZ3WA1b simulation and POAM III observations; the primary difference is that MZ3-EXP471 starts with larger $\mathrm{O}_{3}$ abundances. This condition, plus the fact that the $\mathrm{O}_{3}$ depletion below $450 \mathrm{~K}$ (see Figure 16a) is underestimated in the MZ3-EXP471 simulation, is the reason why the total column ozone change does not approach the MZ3WA1b result or EP/TOMS values for year 2000.

[49] The differences in the $\mathrm{O}_{3}$ hole simulations noted above when using the three sets of meteorological fields are likely related to differences in temperature and/or in trans- port. To examine this in more detail, the annual evolution of Southern Hemisphere total column ozone and local constituents at $84^{\circ} \mathrm{S}$ are shown in Figure 17. This figure displays the temporal evolution of total column ozone, plus local change at $43 \mathrm{hPa}(\sim 20 \mathrm{~km})$ in $\mathrm{O}_{3}$, inorganic reservoir species $\left(\mathrm{HCl}, \mathrm{ClONO}_{2}\right)$, total inorganic chlorine $\left(\mathrm{ClO}_{y}=\right.$ $\left.\mathrm{ClO}_{x}+\mathrm{HCl}+\mathrm{ClONO}_{2}\right)$, "active" inorganic chlorine $\left(\mathrm{ClO}_{x}=\right.$ $\left.\mathrm{Cl}+2 \mathrm{Cl}_{2}+\mathrm{ClO}+\mathrm{OClO}+2 \mathrm{Cl}_{2} \mathrm{O}_{2}+\mathrm{HOCl}\right), \mathrm{H}_{2} \mathrm{O}$, and $\mathrm{HNO}_{3}$. The figure shows that the available inorganic chlorine contained in $\mathrm{HCl}$ and $\mathrm{ClONO}_{2}$ is significantly activated to $\mathrm{ClO}_{x}$ species in all three simulations. However, $\mathrm{ClO}_{y}$ is not the same in the three simulations. There is a larger abundance of $\mathrm{ClO}_{y}$ in the MZ3-WA1b simulation, followed by the MZ3-EXP471, and MZ3-Op simulations. The amount of $\mathrm{ClO}_{y}$ is strongly dependent on the dynamics and transport, and is proportional to the mean age of air (Figures 4 and 5) [Waugh and Hall, 2002]. The MZ3-WA1b had the oldest mean age of air in the polar latitudes and, consistent with, the greatest amount of $\mathrm{ClO}_{y}$. The MZ3EXP471 simulation underestimated the $\mathrm{ClO}_{y}$ relative to MZ3-WA1b case by $0.2-0.5$ ppbv. However, at this altitude prior to 1 October ( 0.75 year fraction) the temporal evolution of the temperatures is very similar in MZ3-WA1b and MZ3-EXP471 (Figure 3). This condition, along with similar $\mathrm{ClO}_{y}$, is why the $\mathrm{ClO}_{x}$ temporal distributions are consistent and the $\mathrm{O}_{3}$ loss is comparable (but not identical) between the two simulations. A similar conclusion can be made for $\mathrm{BrO}_{y}$ and $\mathrm{BrO}_{x}$ species (not shown). It is also interesting to compare the temporal evolution of $\mathrm{H}_{2} \mathrm{O}$ and $\mathrm{HNO}_{3}$. In Figure 3, the final warming in the Southern Hemisphere polar stratosphere occurs in mid-October when using ECMWF meteorological fields; the WACCM1b case never experienced an abrupt final warming. This allowed the MZ3-WA1b Southern Hemisphere polar vortex to stay isolated longer and slowed the $\mathrm{O}_{3}$ recovery. The persistent MZ3-WA1b Antarctic vortex also affected the late spring/ winter distributions of $\mathrm{ClONO}_{2}, \mathrm{HNO}_{3}$, and $\mathrm{H}_{2} \mathrm{O}$. There was significant denitrification during the winter-spring period and, without replenishment of inorganic nitrogen species from outside the vortex, $\mathrm{ClONO}_{2}$ and $\mathrm{HNO}_{3}$ could not rapidly recover to prewinter values (contrary to what occurred in the MZ3-ECMWF simulations). For $\mathrm{H}_{2} \mathrm{O}$, dehydration processes stopped in midwinter and the amount of $\mathrm{H}_{2} \mathrm{O}$ in the vortex remained relatively constant until mixing of $\mathrm{H}_{2} \mathrm{O}$ rich midlatitude air occurred later in the year (see Figure 14). Overall, the more realistic representation of the final warming in the MZ3-ECMWF simulations (Figure 3) explains the better simulation of the dehydration and recovery of $\mathrm{H}_{2} \mathrm{O}$ relative to observations (see also Figure 14).

\section{Summary and Conclusions}

[50] In order to assess the influence of meteorological input parameters on the calculated atmospheric composition of the atmosphere, we have used an atmospheric chemical transport model driven by three different dynamical fields. The first dynamical data set comes from simulations performed with the Whole Atmosphere Community Climate Model, version $1 \mathrm{~b}$. The second and third sets were provided by the European Centre for Medium-Range Weather Forecasts, and included operational products for year 2000 and a 

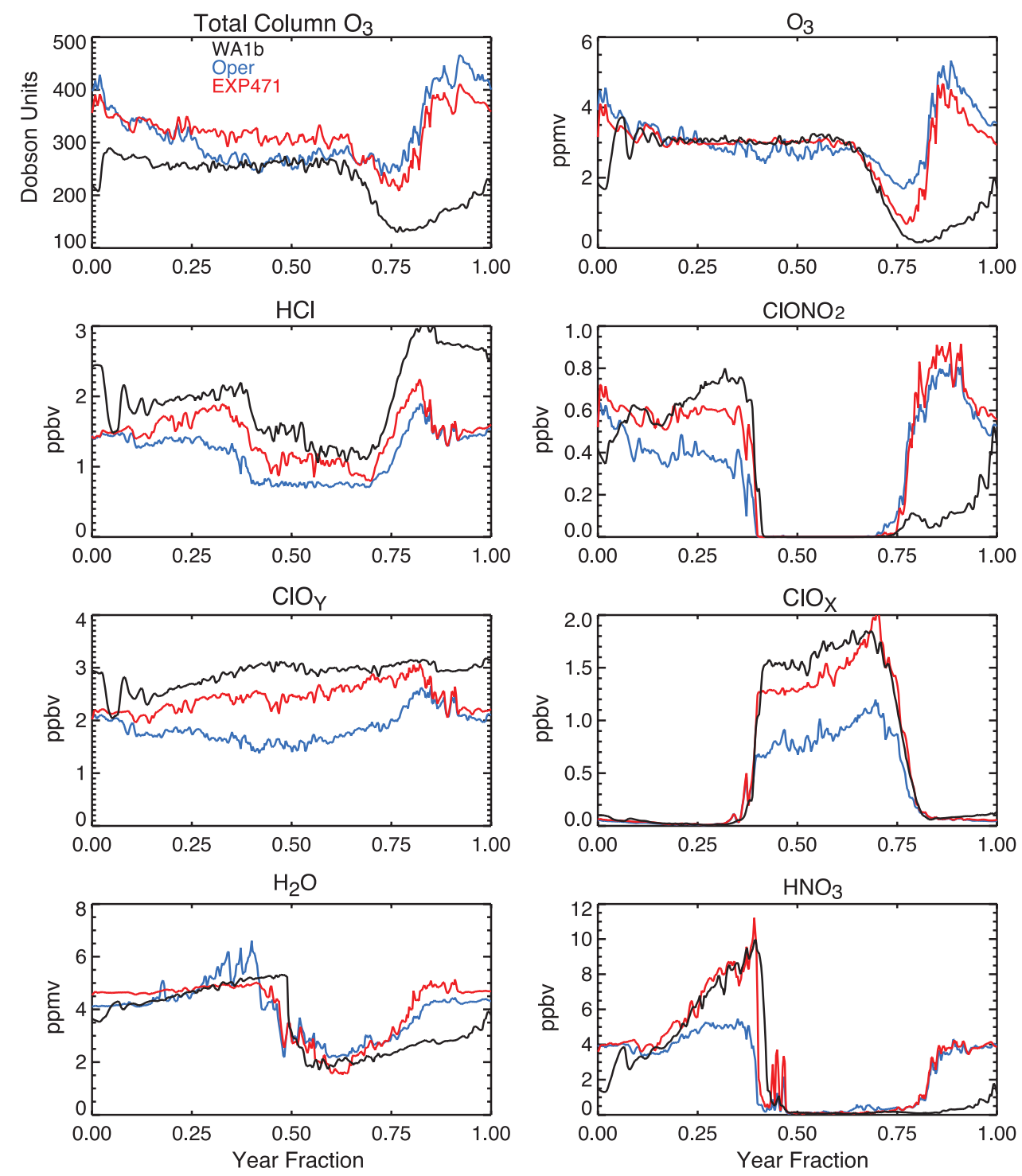

Figure 17. Annual cycles of total column ozone (DU), Ozone (ppmv), $\mathrm{HCl}$ (ppbv), $\mathrm{ClONO}_{2}$ (ppbv), total inorganic chlorine $\left(\mathrm{ClO}_{y}\right)$, active inorganic chlorine $\left(\mathrm{ClO}_{x}\right)$, water vapor (ppmv), and $\mathrm{HNO}_{3}$ (ppbv) at $84^{\circ} \mathrm{S}$ on the $43 \mathrm{hPa}$ pressure surface. Black line is for MZ3-WA1b; blue line is for MZ3-Op; and red line is for MZ3-EXP471.

recent reanalysis, called EXP471, which is an update for year 2000 of the ERA-40 reanalysis. The fields retained in the case of WACCM1b correspond to a specific simulation year that bears resemblance to observed conditions in year 2000; however, it should be emphasized that it is not a detailed simulation of this or any other specific year.

[51] A detailed analysis of the chemical fields simulated by MOZART-3 shows that, even though the general features characterizing the three dynamical sets are rather similar, slight differences in winds and temperature can produce substantial differences in the calculated distributions of chemical tracers. This study shows that, in most cases, the ECMWF operational wind fields produce too strong latitudinal mixing and therefore too weak dynamical barriers against meridional transport. This behavior is reflected in the calculated mean age of air, which at $20 \mathrm{~km}$ in the extratropics is $1-3$ years lower than the values derived from the observations of long-lived tracers. The EXP471 reanalysis benefits from many of the improvements made to ECMWF's operational analysis system since the year 2000 , and produces much more realistic distributions of stratospheric tracers consistent with much improved values of the mean age of air. The tracer distributions calculated when the WACCM1b meteorological fields are specified adequately represents observed tracer distributions and the mean age of air. Meteorological quantities provided by general circulation models with no observational constraints seem in many cases to provide more realistic results than quantities resulting from data assimilation procedures. This has been shown in previous studies to be due to undesirable noise or imbalance generated by the assimilation procedure, 
which has considerable effects on the model-simulated transport of chemical species.

[52] The photochemical lifetimes for selective short-lived $(<10$ years) and long-lived species are also shown for the three model simulations. The MZ3-WA1b simulation produces lifetimes of long-lived species (e.g., CFC-11, CFC12 , and $\mathrm{N}_{2} \mathrm{O}$ ) that are closet to the values derived from observations, followed by the MZ3-EXP471 and MZ3-Op simulations respectively. In contrast, the $\mathrm{CH}_{4}$ photochemical lifetime, which is less than 10 years and controlled mainly by the reaction with tropospheric $\mathrm{OH}$, is best represented by MZ3-EXP471 simulation.

[53] Even though the tropical total ozone columns calculated in the three model cases are in fair agreement with observations, the calculations of vertical and horizontal exchanges in the tropics are not satisfactory. In the tropical lower-to-middle stratosphere, there are differences between the three model cases when the $\mathrm{H}_{2} \mathrm{O}$ tape recorder signal is analyzed. The phase lag of the dry component of the tape recorder signal is best represented by the MZ3-WA1b simulation. Both the MZ3-ECMWF simulations propagate the tape recorder signal too rapidly compared to observations. In the tropical midstratosphere region (near $10 \mathrm{hPa}$ ), the temporal evolution and magnitude of $\mathrm{NO}_{y}$ is very different between the MZ3-ECMWF simulations and the MZ3-WA1b simulation. In the latter case, minimum $\mathrm{NO}_{y}$ values are centered on the equator. These values tend to underestimate substantially the observed UARS climatology. Since $\mathrm{O}_{3}$ is primarily controlled by $\mathrm{NO}_{y}$ chemistry in this region, the $\mathrm{O}_{3}$ distribution for the MZ3-WA1b simulation is centered on the equator and is overestimated relative to the UARS climatology. The MZ3-ECMWF simulations minimum $\mathrm{NO}_{y}$ values are not centered on the equator and their distributions are influenced by the QBO secondary circulation for year 2000. The $\mathrm{O}_{3}$ abundance in these simulations also follows the latitudinal and temporal structure of $\mathrm{NO}_{y}$. This was confirmed by examining the TEM vertical and horizontal velocities. If the WACCM1b parent GCM had included a QBO, the tracer distributions and $\mathrm{O}_{3}$ would have been represented much better. We have recently confirmed the importance of the QBO circulation in simulations with a fully coupled version of WACCM, which will be the focus of a future study.

[54] Large differences between model results are also apparent at high latitudes. In all cases, the total column ozone appears to be overestimated during all seasons north of $40^{\circ} \mathrm{N}$ and in the latitude band of $60^{\circ} \mathrm{S}$ where the southern hemispheric maximum in the total column ozone is observed. Again, this suggests that the Brewer-Dobson circulation in the three model cases is too strong. Only the MOZART-3 simulation driven with WACCM1b dynamical data produces total column ozone amounts in reasonable agreement with observations in the Southern Hemisphere.

[55] The differences in the three meteorological data sets also lead to very different representations of the springtime Antarctic $\mathrm{O}_{3}$ hole. Although the Southern Hemisphere polar winter and early spring lower stratosphere temperatures are similar in the three cases, the intensity of the meridional circulation and the degree of isolation of the polar vortex are different. In the two ECMWF cases, the final warming occurs at the time constrained by observations, while in WACCM1b, the transition between winter and summer conditions occurs in a considerably less abrupt fashion and takes place about a month later than observations for year 2000 would indicate. The depth of the $\mathrm{O}_{3}$ hole is considerably underestimated in the two cases using assimilated dynamics, especially in the case of the operational data. This is attributed to the excessively vigorous transport of $\mathrm{O}_{3}$, which partly replenishes the $\mathrm{O}_{3}$ that has been catalytically destroyed by chlorine compounds in the polar region. The isolation of the polar vortex is more pronounced when WACCM1b data are used, so that more ozone is destroyed. In addition, the level of inorganic chlorine and bromine is quite different in the three cases under consideration. In simulations with relatively low mean age of air, the level of inorganic chlorine and bromine at high latitudes is lower than in cases with higher mean age of air. As a result, the calculated chemical $\mathrm{O}_{3}$ destruction rate by halogen radicals is four times higher when the MOZART3 model is driven by WACCM1b data than, for example, when the model uses the ECMWF operational data. In the MOZART-3 simulation using WACCM1b meteorological fields, the vortex remains stable for several weeks in spring and large $\mathrm{O}_{3}$ depletion is derived. However, since the vortex remains isolated later into the spring, the $\mathrm{O}_{3}$ hole persists until the end of November.

[56] Acknowledgments. This paper is dedicated to the memory of our friend and colleague Byron A. Boville. We would also like to thank the anonymous reviewers for their insightful comments. Douglas E. Kinnison would like to acknowledge partial support from the NASA EOA Aura Program. The National Center for Atmospheric Research is sponsored by the U.S. National Science Foundation.

\section{References}

Andrews, A. E., et al. (2001), Mean ages of stratospheric air derived from in situ observations of $\mathrm{CO}_{2}, \mathrm{CH}_{4}$, and $\mathrm{N}_{2} \mathrm{O}, J$. Geophys. Res., 106, 32,29532,314 .

Bey, I., D. J. Jacob, R. M. Yantosca, J. A. Logan, B. D. Field, A. M. Fiore, Q. Li, H. Y. Liu, L. J. Mickley, and M. G. Schultz (2001), Global modeling of tropospheric chemistry with assimilated meteorology: Model description and evaluation, J. Geophys. Res., 106, 23,073-23,095.

Boering, K. A., et al. (1996), Stratospheric transport rates and mean age distribution derived from observations of atmospheric $\mathrm{CO}_{2}$ and $\mathrm{N}_{2} \mathrm{O}$, Science, 274, 1340-1343.

Brasseur, G. P., and S. Solomon (2005), Aeronomy of the Middle Atmosphere, Chemistry and Physics of the Stratosphere and Mesosphere, 3rd ed., Springer, New York.

Brasseur, G. P., X. X. Tie, P. J. Rasch, and F. Lefevre (1997), A threedimensional simulation of the Antarctic ozone hole: Impact of anthropogenic chlorine on the lower stratosphere and upper troposphere, J. Geophys. Res., 102, 8909-8930.

Brasseur, G. P., D. A. Hauglustaine, S. Walters, P. J. Rasch, J.-F. Muller, C. Granier, and X.-X. Tie (1998), MOZART: A global chemical transport model for ozone and related chemical tracers: 1 . Model description, J. Geophys. Res., 103, 28,265-28,289.

Chipperfield, M. P., D. Cariolle, P. Simon, R. Ramaroson, and D. J. Lary (1993), A three-dimensional modeling study of trace species in the Arctic lower stratosphere during winter 1989-1990, J. Geophys. Res., 98, $7199-7218$.

Considine, D. B. (2004), Sensitivity of Global Modeling Initiative model predictions of Antarctic ozone recovery to input meteorological fields, J. Geophys. Res., 109, D15301, doi:10.1029/2003JD004487.

Crutzen, P. J., and P. H. Zimmerman (1991), The changing photochemistry of the troposphere, Tellus, 43, 136-151.

Douglass, A. R., R. B. Rood, S. R. Kawa, and D. J. Allen (1997), A threedimensional simulation of the evolution of the middle latitude winter ozone in the middle stratosphere, J. Geophys. Res., 102, 19,217-19,232.

Douglass, A. R., M. J. Prather, T. M. Hall, S. E. Strahan, P. J. Rasch, L. C. Sparling, L. Coy, and J. M. Rodriguez (1999), Choosing meteorological input for the global modeling initiative assessment of high-speed aircraft, J. Geophys. Res., 104, 27,545-27,564.

Douglass, A. R., M. R. Schoeberl, and R. B. Rood (2003), Evaluation of transport in the lower tropical stratosphere in a global chemistry and 
transport model, J. Geophys. Res., 108(D9), 4259, doi:10.1029/ 2002JD002696.

Douglass, A. R., R. S. Stolarski, S. E. Strahan, and P. S. Connell (2004), Radicals and reservoirs in the GMI chemistry and transport model: Comparison to measurements, J. Geophys. Res., 109, D16302, doi:10.1029/ 2004JD004632.

Elkins, J. W., et al. (1996), Airborne gas chromatograph for in situ measurements of long-lived species in the upper troposphere and lower stratosphere, Geophys. Res. Lett., 23, 347-350.

Emmons, L. K., et al. (2003), Budget of tropospheric ozone during TOPSE from two chemical transport models, J. Geophys. Res., 108(D8), 8372, doi:10.1029/2002JD002665.

Eyring, V., et al. (2006), Assessment of temperature, trace species, and ozone in chemistry-climate model simulations of the recent past, J. Geophys. Res., 111, D22308, doi:10.1029/2006JD007327.

Forkman, P., P. Ericksson, A. Winnberg, R. R. Garcia, and D. E. Kinnison (2003), Longest continuous ground-based measurements of mesospheric CO, Geophys. Res. Lett., 30(10), 1532, doi:10.1029/2003GL016931.

Garcia, R. R., D. R. Marsh, D. E. Kinnison, B. A. Boville, and F. Sassi (2007), Simulation of secular trends in the middle atmosphere, 1950 2003, J. Geophys. Res., 112, D09301, doi:10.1029/2006JD007485.

Gettelman, A., and A. H. Sobel (2000), Direct diagnoses of stratospheretroposphere exchange, J. Atmos. Sci., 57, 3-16.

Gettelman, A., D. E. Kinnison, G. Brasseur, and T. Dunkerton (2004), Impact of monsoon circulations on the upper troposphere and lower stratosphere, J. Geophys. Res., 109, D22101, doi:10.1029/2004JD004878.

Hall, T. M., and R. A. Plumb (1994), Age as a diagnostic of stratospheric transport, J. Geophys. Res., 99, 1059-1070.

Hall, T. M., D. W. Waugh, K. A. Boering, and A. R. Plumb (1999), Evaluation of transport in stratospheric models, J. Geophys. Res., 104, 18,81518,839 .

Happel, J. D., and M. P. Roche (2003), Soils: A global sink of atmospheric carbon tetrachloride, Geophys. Res. Lett., 30(2), 1088, doi:10.1029/ 2002 GL015957.

Hauglustaine, D. A., G. P. Brasseur, S. Walters, P. J. Rasch, J-.F. Müller, L. K. Emmons, and M. A. Carroll (1998), MOZART: A global chemical transport model for ozone and related chemical tracers: 2. Model results and evaluation, J. Geophys. Res., 103, 28,291-28,335.

Haynes, P., H. C. J. Marks, M. E. McIntyre, T. G. Shepherd, and K. P. Shine (1991), On the "downward control" of extratropical diabatic circulations and eddy-induced mean zonal forces, J. Atmos. Sci., 48, 651-678.

Holton, J. R., P. H. Haynes, M. E. McIntyre, A. R. Douglass, R. B. Rood, and L. Pfister (1995), Stratosphere-troposphere exchange, Rev. Geophys., 33, 403-439.

Horowitz, L. W., et al. (2003), A global simulation of tropospheric ozone and related tracers: Description and evaluation of MOZART, version 2, J. Geophys. Res., 108(D24), 4784, doi:10.1029/2002JD002853.

Intergovernmental Panel on Climate Change (2001), Climate Change 2001: The Scientific Basis: Contribution of Working Group I to the Third Assessment Report of the Intergovernmental Panel on Climate Change, edited by J. T. Houghton, Cambridge Univ. Press, New York.

Kulawik, S. S., et al. (2006), TES atmospheric profile retrieval characterization: An orbit of simulated observations, IEEE Trans. Geosci. Remote Sens., 44, 1324-1333.

Lamarque, J.-F., J. T. Kiehl, C. Shields, B. A. Boville, and D. E. Kinnison (2006), Modeling the response to changes in tropospheric methane concentrations: Application to the Permian-Triassic boundary, Paleoceanography, 21, PA3006, doi:10.1029/2006PA001276.

Lawrence, M. G., P. J. Crutzen, P. J. Rasch, B. E. Eaton, and N. M. Mahowald (1999), A model for studies of tropospheric photochemistry: Description, global distributions, and evaluation, J. Geophys. Res., 104, 26,245-26,277.

Lefèvre, F., G. P. Brasseur, I. Folkins, A. K. Smith, and P. Simon (1994), Chemistry of the 1991-1992 stratospheric winter: Three-dimensional model simulations, J. Geophys. Res., 99, 8183-8196.

Levy, H., J. D. Mahlman, and W. J. Moxim (1985), Tropospheric ozone: The role of transport, J. Geophys. Res., 90, 3753-3772.

Lin, S. J., and R. B. Rood (1996), A fast flux form semi-Lagrangian transport scheme on the sphere, Mon. Weather Rev., 124, 2046-2070.

Lucke, R. L., et al. (1999), The Polar Ozone and Aerosol Measurement (POAM III) instrument and early validation results, J. Geophys. Res., 104, 18,785-18,799.

Lumpe, J. D., R. M. Bevilacqua, K. W. Hoppel, and C. E. Randall (2002), POAM III retrieval algorithm and error analysis, J. Geophys. Res., 107(D21), 4575, doi:10.1029/2002JD002137.

Lumpe, J., et al. (2006), Validation of Polar Ozone and Aerosol Measurement (POAM) III version 4 stratospheric water vapor, J. Geophys. Res., 111, D11301, doi:10.1029/2005JD006763.

Mahowald, N. M., R. A. Plumb, P. J. Rasch, J. del Corral, F. Sassi, and W. Heres (2002), Stratospheric transport in a three-dimensional isentropic coordinate model, J. Geophys. Res., 107(D15), 4254, doi:10.1029/ 2001JD001313.

Marsh, D., A. Smith, and D. Noble (2003), Mesospheric ozone response to changes in water vapor, J. Geophys. Res., 108(D3), 4109, doi:10.1029/ 2002JD002705.

Marsh, D. R., R. R. Garcia, D. E. Kinnison, B. A. Boville, S. Walters, K. Matthes, and S. C. Solomon (2007), Modeling the whole atmosphere response to solar cycle changes in radiative and geomagnetic forcing, J. Geophys. Res., doi:10.1029/2006JD008306, in press.

McLinden, C. A., S. C. Olsen, B. Hannegan, O. Wild, M. J. Prather, and J. Sundet (2000), Stratospheric ozone in 3-D models: A simple chemistry and the cross-tropopause flux, J. Geophys. Res., 105, 14,653-14,666.

McPeters, R. D., P. K. Bhartia, A. J. Krueger, and J. R. Herman (1998), Earth Probe Total Ozone Mapping Spectrometer (TOMS) Data Product User's Guide, NASA Tech. Publ., NASA/TP-1998-206895.

Monge-Sanz, B. M., M. P. Chipperfield, A. J. Simmons, and S. M. Uppala (2007), Mean age of air and transport in a CTM: Comparison of different ECMWF analyses, Geophys. Res. Lett., 34, L04801, doi:10.1029/ 2006GL028515

Müller, J.-F., and G. P. Brasseur (1995), IMAGES: A three-dimensional chemical transport model of the global troposphere, J. Geophys. Res., 100, 16,445-16,490.

Pan, L. L., W. J. Randel, B. L. Gary, M. J. Mahoney, and E. J. Hintsa (2004), Definition and sharpness of the extratropical tropopause: A trace gas perspective, J. Geophys. Res., 109, D23103, doi:10.1029/2004JD004982.

Pan, L. L., J. C. Wei, D. E. Kinnison, R. R. Garcia, D. J. Wuebbles, and G. P. Brasseur (2007), A set of diagnostics for evaluating chemistryclimate models in the extratropical tropopause region, J. Geophys. Res., 112, D09316, doi:10.1029/2006JD007792.

Park, J. H., M. K. W. Ko, C. H. Jackman, R. A. Plumb, J. A. Kaye, and K. H. Sage (Eds.) (1999), Models and measurements intercomparison II, NASA Tech. Memo., NASA/TM-1999-209554.

Park, M., W. R. Randel, D. E. Kinnison, R. R. Garcia, and W. Choi (2004), Seasonal variations of methane, water vapor, ozone, and nitrogen dioxide near the tropopause: Satellite observations and model simulations, J. Geophys. Res., 109, D03302, doi:10.1029/2003JD003706.

Penner, J. E., C. S. Atherton, J. Dignon, S. J. Ghan, J. J. Walton, and S. Hameed (1991), Tropospheric nitrogen: A three-dimensional study of sources, distributions, and deposition, J. Geophys. Res., 96, 959-990.

Randall, C. E., et al. (2003), Validation of POAM III ozone: Comparisons with ozonesonde and satellite data, J. Geophys. Res., 108(D12), 4367, doi:10.1029/2002JD002944.

Randel, W. J., F. Wu, J. M. Russell III, A. Roche, and J. W. Waters (1998), Seasonal cycles and QBO variations in stratospheric $\mathrm{CH}_{4}$ and $\mathrm{H}_{2} \mathrm{O}$ observed in UARS HALOE data, J. Atmos. Sci., 55, 163-185.

Randel, W. J., F. Wu, S. J. Oltmans, K. Rosenlof, and G. E. Nedoluha (2004), Interannual changes of stratospheric water vapor and correlations with tropical tropopause temperatures, J. Atmos. Sci., 61, 2133-2148.

Rasch, P. J., X. X. Tie, B. A. Boville, and D. L. Williamson (1994), A threedimensional transport model for the middle atmosphere, J. Geophys. Res., 99, 999-1018.

Rasch, P. J., N. M. Mahowald, and B. E. Eaton (1997), Representations of transport, convection, and the hydrological cycle in chemical transport models: Implications for the modeling of short-lived and soluble species, J. Geophys. Res., 102, 28,127-28,138.

Ray, E., et al. (1999), Transport into the Northern Hemisphere lowermost stratosphere revealed by in situ tracer measurements, J. Geophys. Res., 104, 26,565-26,580.

Roelofs, G.-J., and J. Lelieveld (1995), Distribution and budget of $\mathrm{O}_{3}$ in the troposphere calculated with a chemistry general circulation model, J. Geophys. Res., 100, 20,983-20,998.

Rose, K., and G. P. Brasseur (1989), A three-dimensional model of chemically active species in the middle atmosphere during disturbed winter conditions, J. Geophys. Res., 94, 16,387-16,403.

Rotman, D. A., et al. (2001), Global Modeling Initiative assessment model: Model description, integration, and testing of the transport shell, J. Geophys. Res., 106, 1669-1691.

Rotman, D. A., et al. (2004), IMPACT, the LLNL 3-D global atmospheric chemical transport model for combined troposphere and stratosphere: Model description and analysis of ozone and other trace gases, J. Geophys. Res., 109, D04303, doi:10.1029/2002JD003155.

Sabutis, J. L., and G. L. Manney (2000), Wave propagation in the 1999-2000 Arctic early winter stratosphere, Geophys. Res. Lett., 27(19), 3205-3208. Sassi, F., D. E. Kinnison, B. A. Boville, R. R. Garcia, and R. Roble (2004), Effect of El Niño-Southern Oscillation on the dynamical, thermal, and chemical structure of the middle atmosphere, J. Geophys. Res., 109, D17108, doi:10.1029/2003JD004434.

Sassi, F., B. A. Boville, D. E. Kinnison, and R. R. Garcia (2005), The effects of interactive ozone chemistry on simulations of the middle atmosphere, Geophys. Res. Lett., 32, L07811, doi:10.1029/2004GL022131. 
Schoeberl, M. R., A. R. Douglass, Z. Zhu, and S. Pawson (2003), A comparison of the lower stratospheric age spectra derived from a general circulation model and two data assimilation systems, J. Geophys. Res. 108(D3), 4113, doi:10.1029/2002JD002652.

Schmidt, H., G. P. Brasseur, M. Charron, E. Manzini, M. A. Giorgetta, T. Diehl, V. I. Fomichev, D. E. Kinnison, D. Marsh, and S. Walters (2006), The HAMMONIA chemistry climate model: Sensitivity of the mesospause region to the 11-year solar cycle and $\mathrm{CO}_{2}$ doubling, J. Clim., 19, 3903-3931.

Solomon, S., R. R. Garcia, and F. Stordal (1985), Transport processes and ozone perturbations, J. Geophys. Res., 90, 12,981-12,989.

Thomason, L. W., L. R. Poole, and T. Deshler (1997), A global climatology of stratospheric aerosol surface area density measurements: 1984-1994, J. Geophys. Res., 102, 8967-8976.

Tian, W., M. P. Chipperfield, L. J. Gray, and J. M. Zawodny (2006), Quasibiennial oscillation and tracer distributions in a coupled chemistryclimate model, J. Geophys. Res., 111, D20301, doi:10.1029/2005JD006871.

Tilmes, S., D. E. Kinnison, R. R. Garcia, R. Müller, F. Sassi, D. R. Marsh, and B. A. Boville (2007), Evaluation of heterogeneous processes in the polar lower stratosphere in WACCM3, J. Geophys. Res., doi:10.1029/ 2006JD008334, in press.

Uppala, S. M., et al. (2005), The ERA-40 re-analysis, Q. J. R. Meteorol. Soc., 131, 2961-3012, doi:10.1256/qj.04.176.

van Noije, T. P. C., H. J. Eskes, M. van Weele, and P. F. J. van Velthoven (2004), Implications of the enhanced Brewer-Dobson circulation in European entre for Medium-Range Weather Forecasts reanalysis ERA-40 for the stratosphere-troposphere exchange of ozone in global chemistry transport models, J. Geophys. Res., 109, D19308, doi:10.1029/ 2004JD004586.

Volk, C. M., J. W. Elkins, D. W. Fahey, G. S. Dutton, J. M. Gilligan, M. Loewenstein, J. R. Podolske, K. R. Chan, and M. R. Gunson (1997), Evaluation of source gas lifetimes from stratospheric observations, J. Geophys. Res., 102, 25,543-25,564.

Wang, Y., D. J. Jacob, and J. A. Logan (1998), Global simulation of tropospheric $\mathrm{O}_{3}-\mathrm{NO}_{x}$-hydrocarbon chemistry: 1. Model formulation, J. Geophys. Res., 103, 10,713-10,725.
Waugh, D., and T. Hall (2002), Age of stratospheric air: Theory, observations, and models, Rev. Geophys., 40(4), 1010, doi:10.1029/2000RG000101.

Williamson, D. L. (1997), Climate simulations with a spectral, semiLagrangian model with linear grids, in Numerical Methods in Atmospheric and Ocean Modelling: The Andre J. Robert Memorial Volume, edited by C. Lin, R. Laprise, and H. Ritchie, pp. 279-292, Can. Meteorol. and Oceanogr. Soc., Ont.

Williamson, D. L., and J. G. Olson (1994), Climate simulations with a semi-Lagrangian version of the NCAR Community Climate Model, Mon. Weather Rev., 122, 1594-1610.

World Meteorological Organization (2003), Scientific assessment of ozone depletion: 2002, Global Ozone Res. Monit. Proj. Rep. 47, Geneva.

Yvon-Lewis, S. A., and J. H. Butler (1997), The potential effect of oceanic biological degradation on the lifetime of atmospheric $\mathrm{CH}_{3} \mathrm{Br}$, Geophys. Res. Lett., 24, 1227-1230.

G. P. Brasseur, L. Emmons, R. R. Garcia, A. Gettelman, P. Hess, D. E. Kinnison, J. F. Lamarque, D. R. Marsh, J. J. Orlando, L. L. Pan, W. Randel, F. Sassi, X. X. Tie, and S. Walters, Atmospheric Chemistry Division, National Center for Atmospheric Research, 3450 Mitchell Lane, Boulder, CO 80301, USA. (dkin@ucar.edu)

T. Diehl, NASA Goddard Space Flight Center, Code 613.3, Greenbelt, MD 20771, USA.

C. Granier, Aeronomy Laboratory, 325 Broadway, Boulder, CO 80305 , USA.

V. L. Harvey and C. E. Randall, Laboratory for Atmospheric and Space Physics, University of Colorado, UCB 392, Boulder, CO 80309-0392, USA.

U. Niemeier, Max Planck Institute for Meteorology, Bundesstrasse 53, D-20146 Hamburg, Germany.

A. J. Simmons, European Centre for Medium-Range Weather Forecasts, Shinfield Park, Reading RG2 9AX, UK. 